\title{
El estilo Río Bec visto desde Dzibanché y Kohunlich
}

Le style architectural Río Bec à Dzibanché et Kohunlich

The Río Bec style seen from Dzibanché and Kohunlich

Enrique Nalda y Sandra Balanzario

\section{OpenEdition}

\section{Journals}

Edición electrónica

URL: https://journals.openedition.org/jsa/14072

DOI: 10.4000/jsa.14072

ISSN: 1957-7842

\section{Editor}

Société des américanistes

\section{Edición impresa}

Fecha de publicación: 31 diciembre 2014

Paginación: 179-209

ISSN: 0037-9174

\section{Referencia electrónica}

Enrique Nalda y Sandra Balanzario, «El estilo Río Bec visto desde Dzibanché y Kohunlich», Journal de la Société des américanistes [En línea], 100-2 | 2014, Publicado el 01 enero 2016, consultado el 02 septiembre 2022. URL: http://journals.openedition.org/jsa/14072 ; DOl: https://doi.org/10.4000/jsa. 14072 


\title{
EL ESTILO RÍO BEC VISTO DESDE DZIBANCHÉ Y KOHUNLICH
}

\author{
$\dagger$ Enrique NALDA y Sandra BALANZARIO *
}

Hallazgos recientes (2009) en Dzibanché arrojan nueva luz sobre la relación de este sitio con su vecino más cercano, Kohunlich, y la región Río Bec. Nuevas hipótesis permiten explicar la penetración del estilo arquitectónico Río Bec en un sitio tan distante como Kohunlich, especialmente si se considera la cercanía con Dzibanché, un sitio qué, por su tamaño, fué el sitio de gran dominio. Así mismo se proponen nuevas ideas sobre la dinastía Kan durante el Clásico tardío [Palabras claves: Dzibanché, Kohunlich, Río Bec, dinastía Kan.]

Le style architectural Río Bec à Dzibanché et Kohunlich. Des découvertes récentes (2009) à Dzibanché jettent une lumière nouvelle sur les relations de ce site avec son voisin le plus proche, Kohunlich, ainsi qu'avec la région Río Bec. De nouvelles hypothèses permettent d'expliquer l'intrusion du style architectural Río Bec dans un site éloigné de cette zone comme Kohunlich, et cela en particulier compte tenu de sa proximité avec Dzibanché, un site qui, d'après sa taille, fut un centre dominant. Des idées nouvelles sont également formulées concernant la dynastie Kan au Classique récent [Mots-clés: Dzibanché, Kohunlich, Río Bec, dynastie Kan.]

The Río Bec style seen from Dzibanché and Kohunlich. Recent findings (2009) at Dzibanche throw new light on the relationship of this site with nearby Kohunlich as well as between the latter and the Río Bec region. A new hypothesis is advanced to explain the penetration of the Río Bec architectural style in a site as distant as Kohunlich, especially when considering the nearness of Dzibanché, a site which by its sheer size should be expected to be the central place of a large dominion. New ideas on the whereabouts of the Kan dynastic group in the Late Classic are put forward as well [Key words: Dzibanché, Kohunlich, Río Bec, dynasty Kan.]

* Sandra Balanzario, investigadora adscrita al Centro INAH Quintana Roo [sbalanzario@, yahoo.com] ; Enrique Nalda, investigador adscrito a la Dirección de Estudios Arqueológicos (INAH), obra póstuma $2010 \dagger$.

Journal de la Société des américanistes, 2014, 100-2, pp. 179-209. (C) Société des américanistes. 
Uno de los temas discutidos en los estudios de la cultura maya es el de las relaciones entre los estilos arquitectónicos de Río Bec, Chenes y Puuc. Varios han sido los investigadores interesados en el tema, especialmente Andrews (1987, 1994), Gendrop (1983, 1987), Pollock (1970, 1980) y Potter (1977). Más allá de la cuestión de la definición de los rasgos que caracterizan cada uno de estos estilos -por demás escurridiza-, los problemas planteados alrededor de este tema han sido, fundamentalmente, los del origen y la dirección de la dispersión de esos rasgos. En general, el tema se ha tratado como una cuestión de difusión de rasgos producto de contactos e intrusiones. La discusión del tema se ha desarrollado, sin embargo, sin intentar explicar el carácter de esos contactos, sugiriendo implícitamente que la arquitectura es una expresión con dinámica propia, derivada de la naturaleza humana de inventar y adoptar continuamente ideas externas.

Uno de los principales obstáculos que han encontrado esas investigaciones es la ausencia de una cronología confiable y suficiente, consecuencia de que los procesos involucrados, en especial los que condujeron a la constitución y adopción de los estilos Río Bec y Chenes, se desarrollaron en un periodo relativamente breve, $\mathrm{y}$ al hecho de que existen traslapes temporales entre estilos. Otro más es la distribución espacial indefinida de rasgos estilísticos, la cual no apoya una regionalización clara, pues existe una cantidad importante de sitios en los que se mezclan rasgos de estilos diferentes, y, también, de anomalías en la distribución de sitios de un estilo particular: edificios de un estilo cualquiera en medio de una zona donde predominan construcciones de otro estilo.

La irregularidad de esa dispersión de rasgos es evidente en los esquemas que presentó Gendrop (1983) para dar cuenta de la cobertura territorial de los estilos Río Bec y Puuc. En el correspondiente al estilo Río Bec, además de un agrupamiento alrededor de un centroide (véase abajo), se observa una fuerte dispersión desde sitios tan meridionales como La Tortuga y El Porvenir en el Peten norte, cerca ya de las fronteras de México con Bélice y Guatemala, hasta sitios tan septentrionales como Dzehkabtún y Dzibilnocac, ya dentro de la región Chenes. Igualmente, las tres fases que Gendrop propone para la arquitectura Puuc (la temprana, la caracterizada por la decoración de junquillos, y la terminal, cuyos elemento diagnósticos son el " petatillo », el « encaje », las grecas y los mascarones de Chac), todas ellas conforman distribuciones difusas (ibid., pp. 4849; Figura 1).

Más allá de las tendencias inherentes a la condición del ser humano de producir y reproducir, es posible ver en estas dispersiones otras razones. Podría, por ejemplo, avanzarse la tesis de que la dispersión del estilo Río Bec, estilo manifiesto en sitios concentrados en el área de Xpujil, Hormiguero, Río Bec, Chicanná y Becán, pero que también se observa en sitios muy alejados del área nuclear y en otros francamente aislados, obedece a formas de organización social y de conformación territorial que no son sino productos históricos y adaptativos. El modelo del cuchcabal propuesto por Okoshi (2007) a partir de su análisis de 


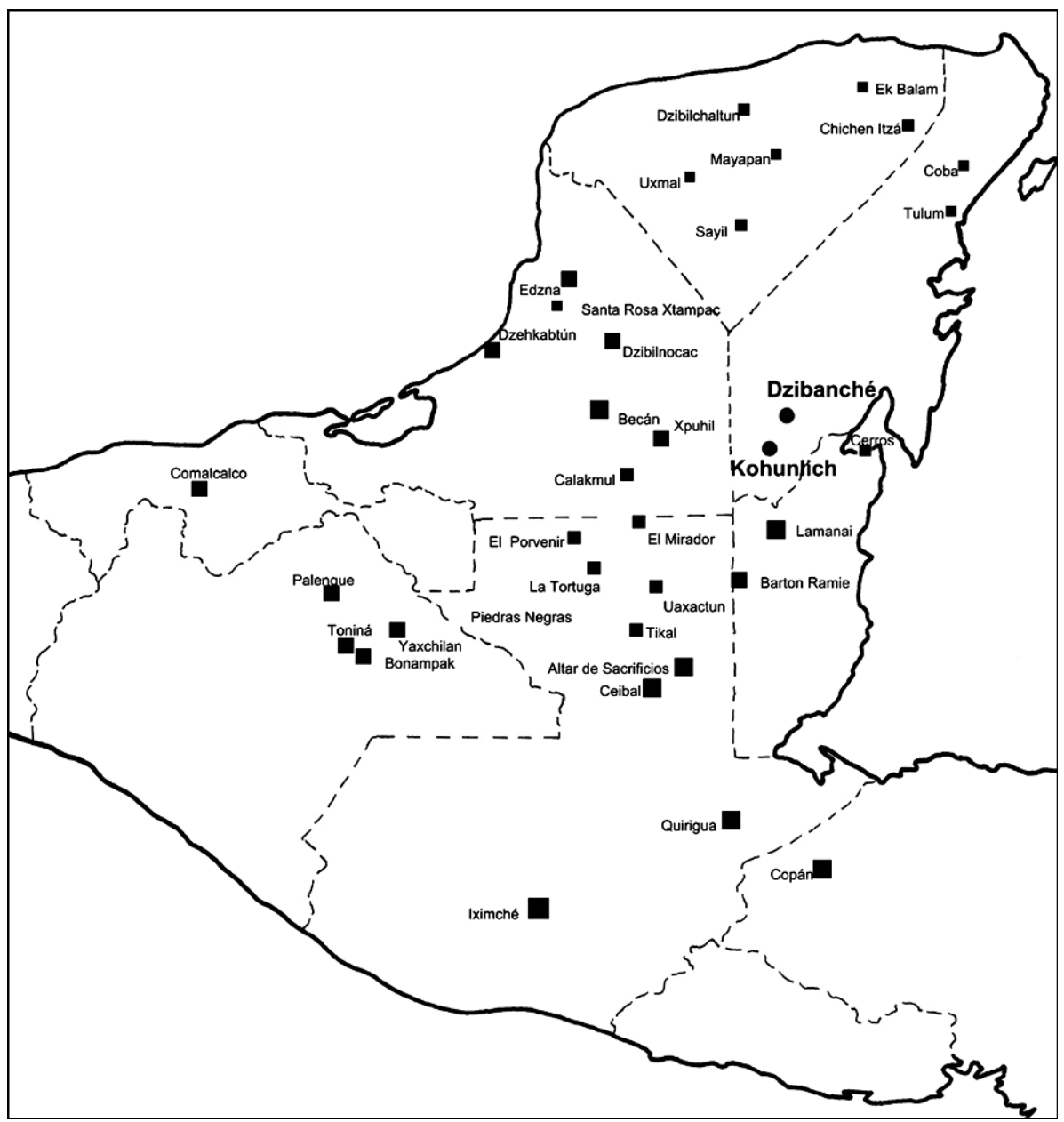

FIG. 1 - Mapa regional mostrando la localización de los sitios mencionados en el texto.

manuscritos de Calkiní se ajusta a esta distribución de sitios y rasgos, distribución que cuestiona la supuesta regla de que la cabecera pierde su capacidad de atracción con la distancia, o, en otros términos, la idea de que los sujetos próximos a una cabecera están relacionados con esa cabecera y no con otra, más distante.

Habría que preguntarse sobre la razón detrás de la irracionalidad aparente, preguntarse sobre el hecho de que sitios muy próximos a centros de población mayor, en ocasiones no tienen relación con esos sitios sino con otros, significativamente más distantes. ¿Cuál es la razón, en otras palabras, de esta 
convivencia de extraños? ¿Qué hizo posible en el despertar del Clásico tardío qué Kohunlich haya optado por formas de expresión cultural típicas de regiones muy distantes al tiempo que se alejaba de las que existían en sitios cercanos como Dzibanché? La respuesta obliga al paso del análisis sincrónico al diacrónico.

No faltan razones que podrían explicar patrones de dispersión de este tipo: pugnas entre grupos de interés, reposicionamientos alrededor de nuevos centros de poder, nuevas alianzas políticas y matrimoniales serían algunas de ellas. Otra posible interpretación al patrón de rasgos arquitectónicos del estilo Río Bec se deriva del modelo de Sahlins (1967), elaborado a partir de su análisis de los linajes segmentarios de los Tiv y Nuer. Según este modelo, la organización de linajes segmentarios responde con eficacia a la necesidad de incorporar tierras ajenas para una población en crecimiento. En la disputa por las nuevas tierras, la organización de linajes segmentarios responde aglomerando segmentos que, en otras circunstancias, operarían de manera independiente e, incluso, como antagónicos. Los segmentos funcionan, de esta manera, como pares en oposición complementaria. Lo que estaríamos viendo en un momento dado sería, según este modelo, una dispersión con asentamientos a diferentes distancias del centro del territorio tribal, algunos de ellos ya ubicados en territorio enemigo. Dispersiones similares de rasgos culturales pueden producirse también por la presencia de comerciantes intercambiando bienes entre comunidades distantes, o por prácticas de reciprocidad entre élites aliadas, o simplemente por la transmisión de bienes de prestigio e ideas en un patrón de dispersión del tipo « múltiples desplazamiento de distancias ». Con frecuencia, tales dispersiones han sido interpretadas bajo el esquema general de « esferas de interacción »y, en casos especiales, bajo el modelo general de " sistema mundo » que no es sino un derivado, con múltiples ajustes, del modelo de «economía mundo » de Wallerstein (1997).

En este texto quisiéramos proponer una interpretación particular a estas inusuales dispersiones de rasgos culturales. Tal alternativa está basada en las diferencias que hemos notado al comparar la arquitectura de Kohunlich con la de Dzibanché, ambos sitios en el sur de Quintana Roo y, sobre todo, al comparar sus respectivos desarrollos históricos durante el Clásico medio y tardío (550850 d.C.). Durante este periodo Kohunlich evolucionó hacia una variabilidad de arquitecturas y proliferación de estilos, entre los que la presencia del estilo Río Bec se exteriorizó en algunos de sus edificios, mientras que el estilo afloró tímidamente en Dzibanché. De esta manera la comparación de las dos historias de arquitecturas monumentales, no solamente en edificios particulares (con sus dimensiones, funciones y asociaciones), sino también en los detalles estilísticos que muestran, lleva a entender las transformaciones políticas en el curso final del Clásico en la franja norte de las tierras bajas centrales, reflejadas en la distribución de estilos arquitectónicos. 


\section{La arquitectura de Kohunlich (Figura 2)}

La arquitectura de Kohunlich del Clásico tardío está marcada por una notoria diversidad.

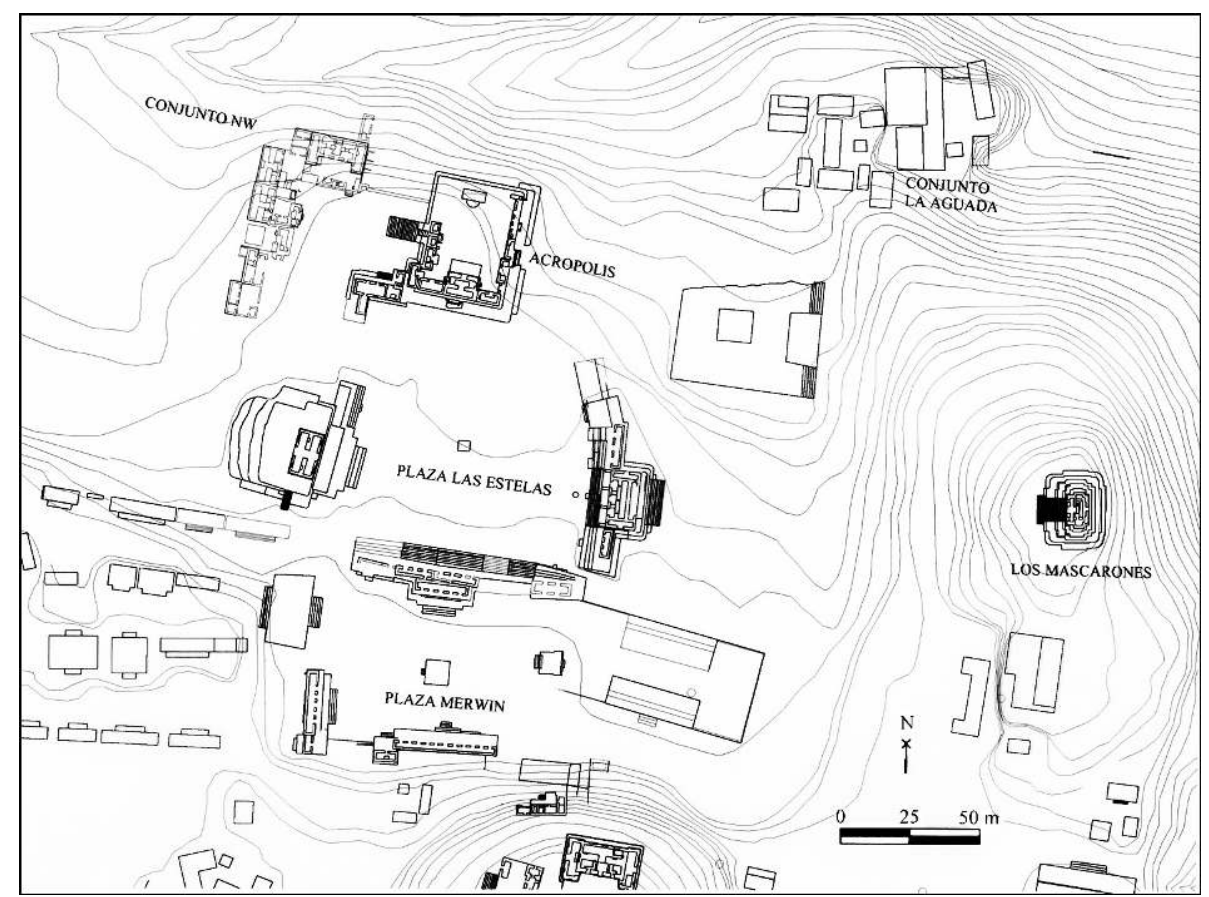

FIG. 2 - Plano del área central de Kohunlich.

En un texto previo presentamos nuestras primeras ideas al respecto (Nalda y Balanzario 2006). La secuencia constructiva de este periodo (600-800 d.C.) inicia con una arquitectura tipo Río Bec y concluye con una serie de proyectos arquitectónicos que integran elementos aislados reconocibles en otras regiones del área maya (Figura 3). Los productos finales retienen, sin embargo, una originalidad que justifica ser tratados como estilos propios.

El estilo Río Bec de Kohunlich, únicamente se encuentra en la sub-estructura de la llamada Acrópolis, así como en un pequeño edificio en el extremo poniente del Juego de Pelota. De la Acrópolis ${ }^{1}$ se preservan dos torres atípicas (Andrews 1987), sin templo que las remate; tienen escaleras simuladas, esquinas redondeadas y molduras de atadura, distribuidas uniformemente a todo lo alto de las 


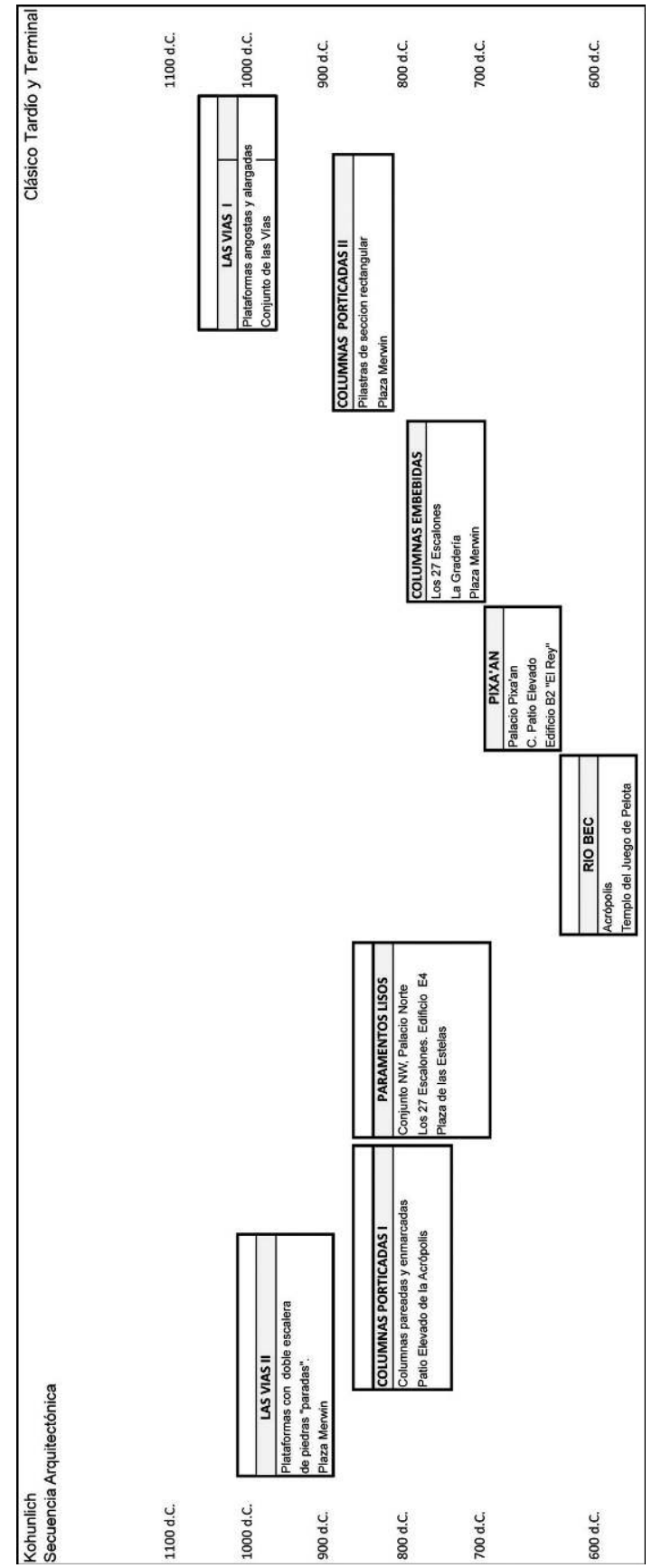

FIG. 3 - Secuencia constructiva de Kohunlich durante el Clásico tardío-terminal. 
torres. El edificio de la Acrópolis es un conjunto de galerías formadas por cuartos abovedados que se cierran a cerca de $8 \mathrm{~m}$ sobre el nivel de su piso; la fachada oriente está decorada con molduras horizontales que prolongan las que adornan la torre asociada; tales molduras se combinan con elementos verticales que se ajustan al diseño general de las torres. Finalmente, en la esquina noreste de esta misma fachada se colocó una especie de contrafuerte que más que elemento que asegure la estabilidad estructural parece operar como elemento decorativo adicional (Figuras 4 y 5).

Sobre el nivel de remate de estas torres fueron construidos otros cuartos, todos ellos alrededor de un patio. Cinco de estos últimos cuartos muestran rasgos compartidos: moldura basal con grupos de tres tamborcillos enmarcados, jambas redondeadas y columnas esquineras embebidas (Figuras 6 y 7).

Con base en estos rasgos, típicos de la arquitectura Río Bec según Andrews, este autor consideró que columnas y cuartos eran partes integrantes de un mismo proyecto arquitectónico y, por tanto, contemporáneos (Andrews 1987, p. 28). Debe tomarse en cuenta, sin embargo, que el paño externo de los muros de estos cuartos (colapsados prácticamente en su totalidad) forzosamente se habría proyectado verticalmente, más allá del remate de las torres ${ }^{2}$. Adicionalmente, hay que considerar que las galerías del edificio y los paramentos asociados a sus fachadas fueron embutidos para crear un gran basamento, conformando la plataforma de sustentación, en la que desplantan los cuartos del Conjunto del Patio Elevado. No puede, por tanto, postularse que los cuartos en el patio elevado y torres estilo Río Bec sean contemporáneos. La confusión de Andrews parece ser consecuencia de que nunca vio explorados y restaurados -como se ven hoy díalos cuartos alrededor del Patio Elevado, ni los desplomes que se produjeron al retiro del relleno de los cuartos asociados a las columnas, los cuales permiten ahora ver con claridad la relación entre cuartos de ambas fases constructivas. La distancia temporal entre ambas fases puede ser corta o larga, pero no puede soslayarse el que sean términos independientes de una secuencia.

En apoyo a esta tesis debe señalarse que, en un texto posterior, el mismo Andrews (1994) considera a las columnas esquineras como típicas del estilo Chenes y anómalas para el Río Bec; igualmente interesante resulta el que ya en 1985 este autor presenta a los tamborcillos agrupados en las molduras basales como típicos del estilo Río Bec, pero frecuentes en la arquitectura Chenes. Es de hacerse notar, también, la presencia de jambas redondeadas, un rasgo común en Edzná, sitio con el cual Kohunlich comparte muchos rasgos de su arquitectura (Nalda y Balanzario 2006). Finalmente, debe señalarse que el elemento quizás más distintivo de la arquitectura de los cuartos en el Patio Elevado de la Acrópolis de Kohunlich (ver más adelante) -los nichos decorando sus fachadasno está incluido en las listas elaboradas por Andrews para dar cuenta de lo particular a cada uno de los estilos que estudia (Río Bec, Chenes, Chenes-Puuc, Puuc temprano y tardío), sin duda por tratarse de un rasgo «atípico » en 


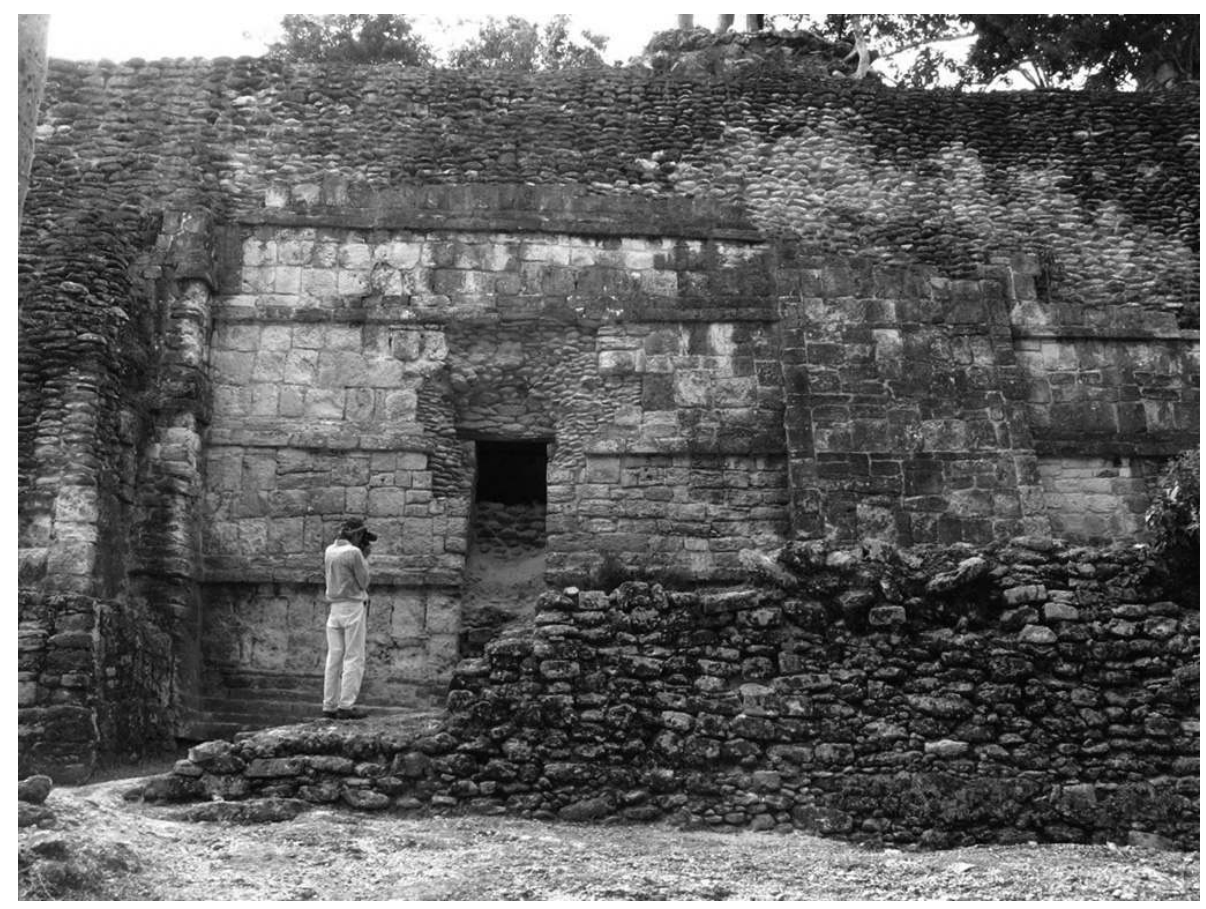

FIG. 4 - Kohunlich, fachada oriente de la Acrópolis (fotografía cortesía del Proyecto Arqueológico Dzibanché-Kohunlich 2009).

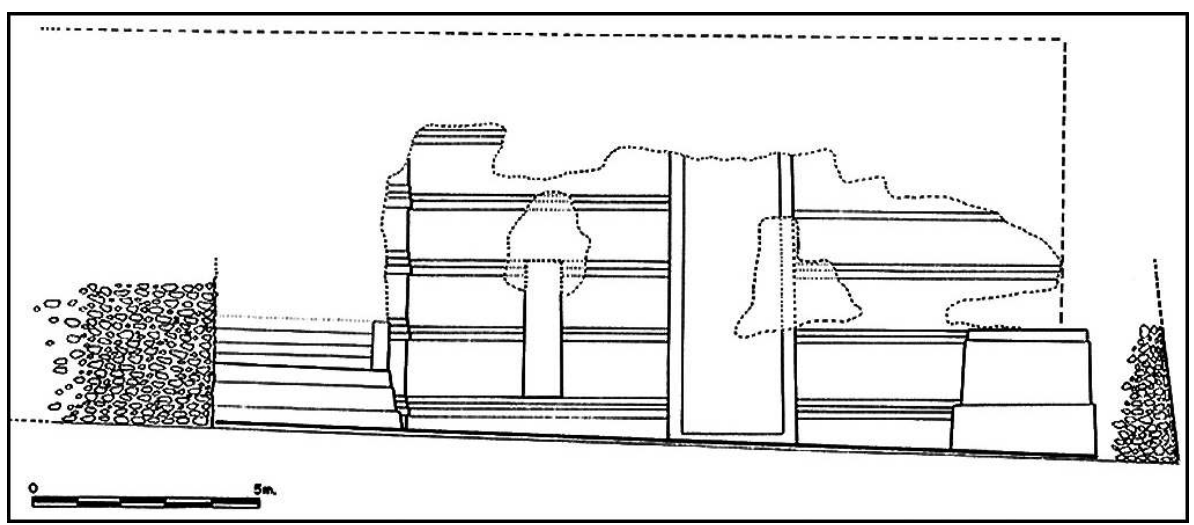

FIG. 5 - Kohunlich, fachada oriente de la Acrópolis (dibujo del Proyecto Sur de Quintana Roo 1997). 


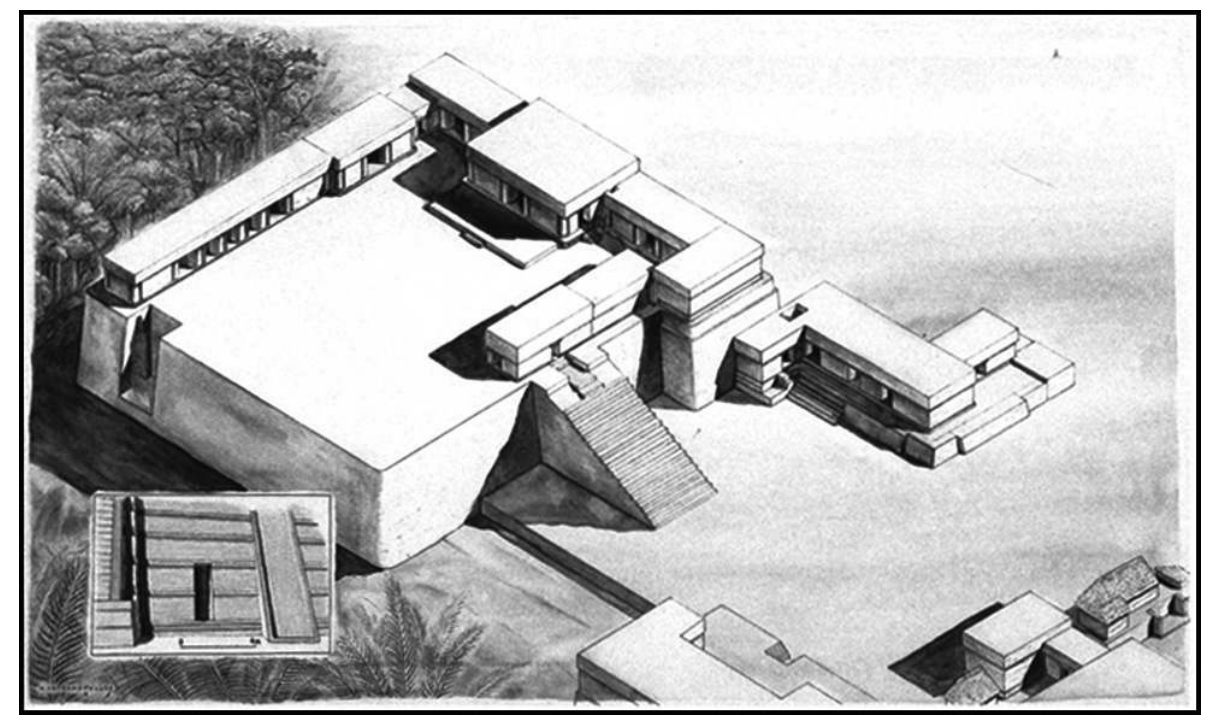

FIG. 6 - Kohunlich, dibujo reconstructivo del Conjunto del Patio Elevado. Orientación Poniente. Dibujo: Nicolas Latsanopoulos (Proyecto Arqueológico Dzibanché-Kohunlich 1999).

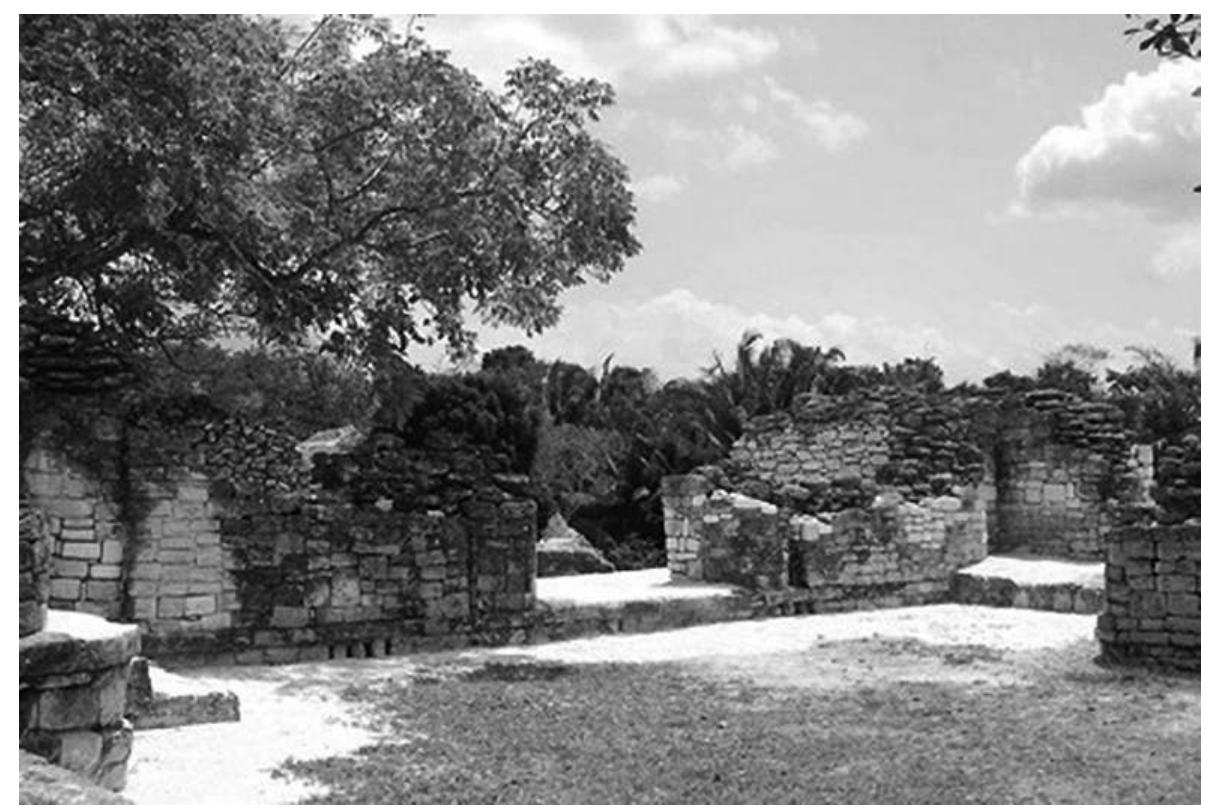

FIG. 7 - Kohunlich, Edificio Sureste del Conjunto del Patio Elevado (fotografía cortesía del Proyecto Arqueológico Dzibanché-Kohunlich 2009). 
cualquiera de ellos. Todo esto señala una proximidad formal entre la arquitectura de Kohunlich y la de la zona Chenes, más clara que la que pudo haber mantenido con el área de Río Bec; marca también una fuerte dosis de desarrollo local en la arquitectura de Kohunlich del Clásico tardío.

En nuestra opinión, los cuartos alrededor del Patio Elevado de la Acrópolis de Kohunlich responden a un estilo particular. Lo conocemos como " estilo Pixa'an » por ser en el complejo habitacional de ese mismo nombre donde se encuentra su ejemplo más completo. El edificio en cuestión es una estructura de paramentos lisos revestidos de pequeños sillares -bien cortados y colocados sin mezcla aparente-, jambas redondeadas en el vano central, molduras basales enmarcando tamborcillos planos, columnas embebidas en las esquinas y plataforma del edificio, y nichos en todas las fachadas (Figuras 8 y 9). El edificio tiene cuatro cuartos, dos de ellos proyectados más allá de la fachada del bloque central; están equipados con banquetas y amplios nichos en su interior, lo que da al proyecto arquitectónico carácter residencial.

Además del Complejo habitacional Pixa'an y de los edificios en la mitad sur del Patio Elevado de la Acrópolis, el estilo aparece en la estructura monumental que bordea el costado poniente de la Plaza de las Estelas; este último es, de hecho, una réplica exacta del edificio mencionado en el complejo Pixa'an. Variantes del mismo se encuentran en otros edificios del sitio: en los complejos habitacionales Nororeste y de los 27 Escalones, así como en el Conjunto Norte. Son estos últimos ejemplos en los que se advierte la ausencia de uno o varios de los rasgos presentes en la versión «típica », verdaderas simplificaciones del proyecto tipo Pixa'an, quizás por ser construcciones más tardías. En efecto, la arquitectura más tardía de la primera fase del Clásico tardío muestra una tendencia hacia la austeridad: aplicado a la arquitectura doméstica, el estilo Pixa'an es remplazado por una propuesta en la que las banquetas ocupan un área mayor, los elementos decorativos en el exterior se eliminan, y las fachadas son revestidas con piedras careadas, ajustadas con cuñas y colocadas con gruesas juntas de acalche y sascab (mortero de cal y arena); la elegancia da paso a la funcionalidad, un cambio entendible si se considera que hacia esas fechas Kohunlich alcanzaba su clímax demográfico.

En la segunda mitad del Clásico tardío (700-800 d.C.), aparece un nuevo estilo que hemos interpretado como indicador de un nuevo desplazamiento poblacional. En ese estilo las columnas embebidas se colocan en la fachada principal y ya no en las esquinas, como en el estilo Pixa'an. Una variante de este estilo es el de las fachadas porticadas con columnas achatadas hacia el espacio interior, pareadas y enmarcadas, y columnas embebidas en los extremos de la misma fachada; estratigráficamente es posterior al estilo Pixa'an en el Patio Elevado de la Acrópolis. Se encuentra presente en la Plaza de las Estelas y, de manera especial, en el costado norte de la Plaza Merwin (Figura 10).

Un estilo más, el de Las Vías, completa el espectro arquitectónico de Kohunlich en el Clásico terminal. Se trata de un estilo (fechado hacia 900 d.C.) en el 


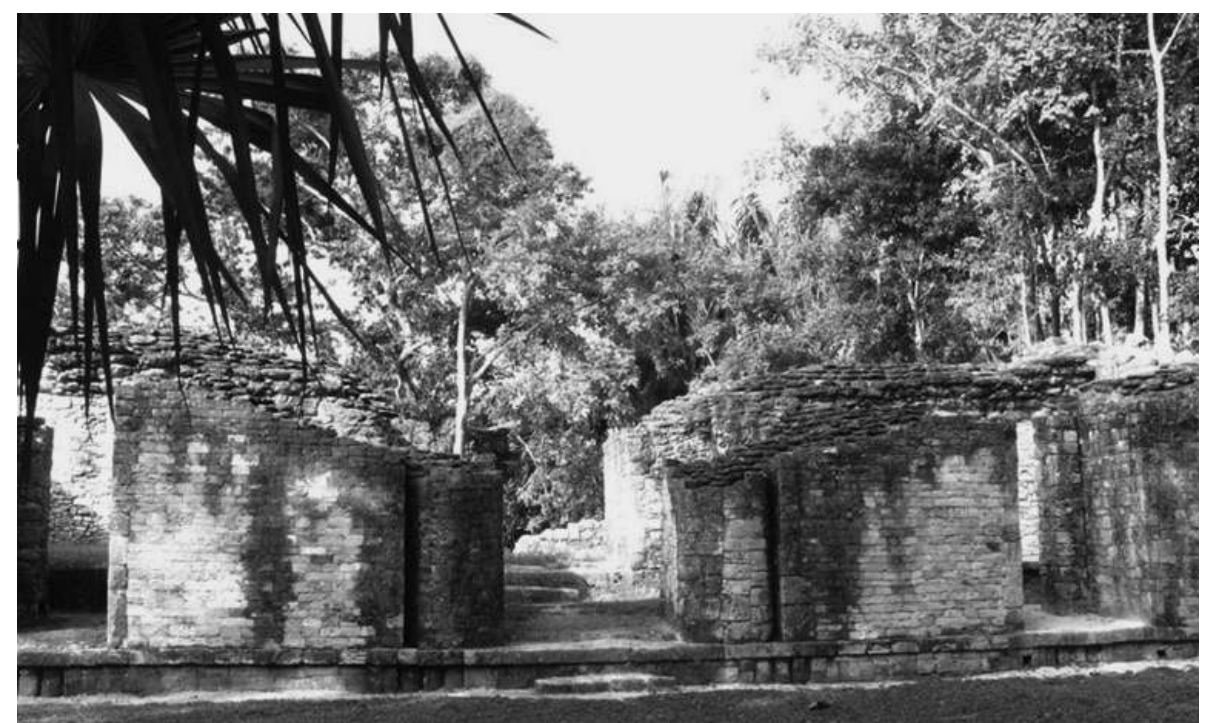

Fig. 8 - Kohunlich, Palacio del Conjunto Pixa'an, fachada sur (fotografía cortesía del Proyecto Arqueológico Dzibanché-Kohunlich 2009).

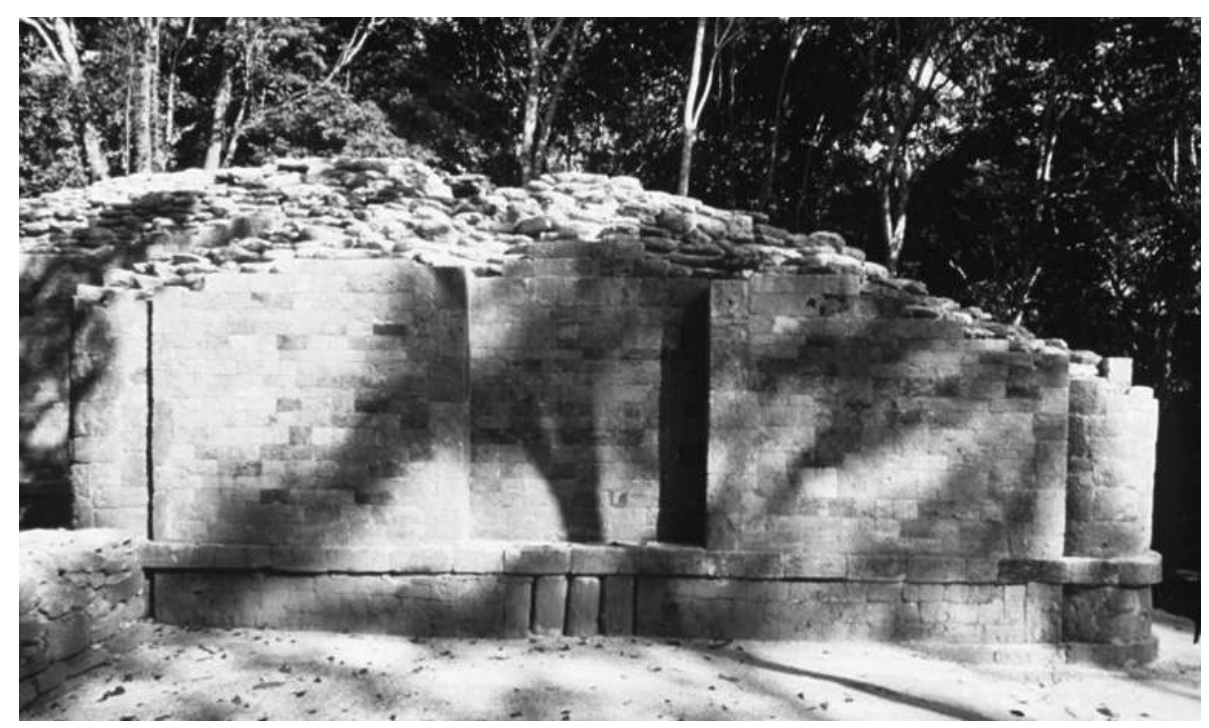

Fig. 9 - Kohunlich, Palacio del Conjunto Pixa'an, fachada lateral poniente (fotografía cortesía del Proyecto Arqueológico Dzibanché-Kohunlich 2009). 


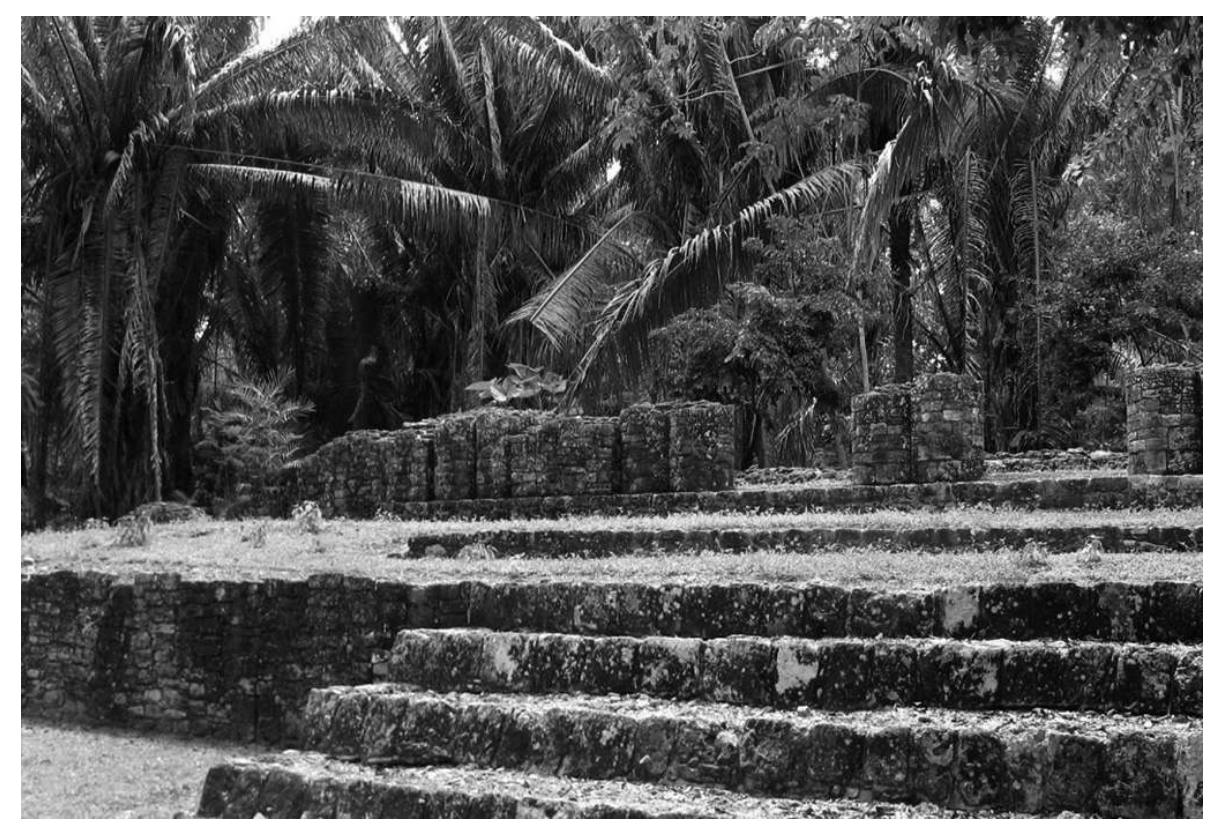

FIG. 10 - Kohunlich, Edificio de las columnas pareadas, Plaza Merwin (fotografía cortesía del Proyecto Arqueológico Dzibanché-Kohunlich 2009).

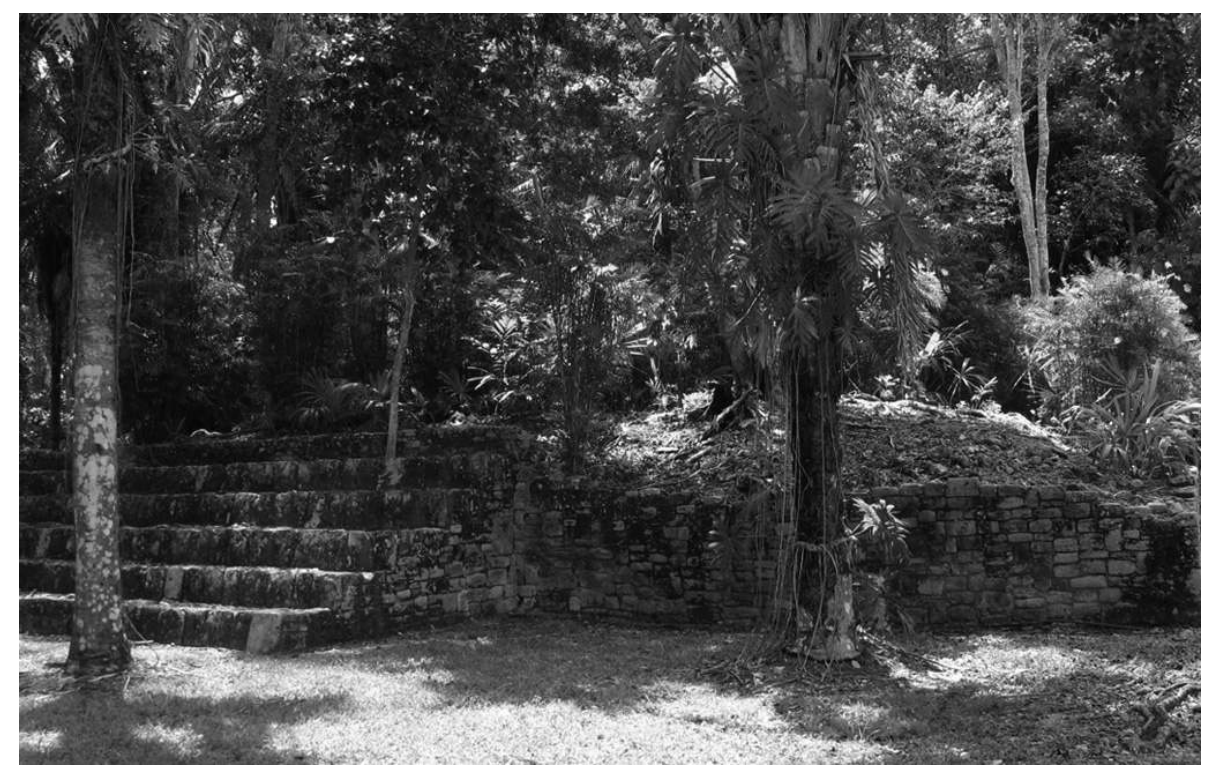

FIG. 11 - Plataforma de doble escalera conformada por « piedras paradas ». Conjunto de Las Vías (fotografía cortesía del Proyecto Arqueológico Dzibanché-Kohunlich 2009). 
que se combinan plataformas angostas y alargadas que se dispusieron en tándem y en líneas paralelas, dejando un estrecho callejón entre líneas adyacentes (de ahí el nombre con que se conoce al estilo), así como estructuras de dimensiones mayores de planta cuadrangular, equipadas con una o dos escaleras de « piedras paradas », ubicadas en fachadas opuestas (Figura 11). Se trata de una propuesta de finales del Clásico que posiblemente se prolongó hasta el abandono de Kohunlich hacia el año 1000/1050 d.C.

El Clásico tardío y terminal, fue la época de mayor crecimiento en la población de Kohunlich, reflejado en su arquitectura y en la construcción de complejos arquitectónicos habitacionales compuestos por 10 a 20 estructuras dispuestas alrededor de patios, presididos por edificios de gran tamaño, o « palacios ». En el área central, existen alrededor de 20 complejos residenciales, tres de ellos se han excavado en su totalidad, se les conoce con los nombres de Conjunto Noroeste, Conjunto Pixa'an y Conjunto de los 27 Escalones; en el resto de los conjuntos se han realizado exploraciones estratigráficas.

En este periodo, Kohunlich se transformó en una sociedad obligada a participar en el intercambio de materias primas esenciales, las cuales se encuentran relativamente distantes. Productos como la miel, cacao y algodón, más que maíz y otros alimentos básicos, debieron haber jugado un papel central en el intercambio que compensaba las deficiencias regionales señaladas: por un lado, entraban a la red de intercambios la sal y productos marinos y lacustres-incluidos bienes de prestigio como espinas de manta raya, conchas y caracoles marinos, quizás en bruto-, y, por otro, alimentos básicos, cacao, algodón, miel y bienes de prestigio terminados, entre ellos artefactos de jadeíta, pirita, acerina y hematita.

Durante el Posclásico Kohunlich continuó habitado por una población menor a la registrada en el Clásico terminal ${ }^{3}$. Continuaron viviendo entre ruinas, acondicionando cuartos y plataformas ubicadas alrededor de los edificios principales o en los conjuntos habitacionales; la presencia de ofrendas del tipo " acumulaciones inusuales», depositadas sobre los pisos y entre derrumbe, confirman la convivencia en cuartos abandonados y cuartos habitados mantenidos adecuadamente. A lo largo de este periodo, sobre los edificios principales los mayas depositaron ofrendas de incensarios y vasijas de los tipos cerámicos Navula y Rojo Tulum.

\section{La arquitectura de Dzibanché (Figura 12)}

No cabe duda que ninguno de los estilos mencionados aparece en Dzibanché. Sólo en uno o dos de los edificios explorados se distinguen rasgos típicos de la arquitectura Río Bec o Chenes (o, en todo caso, Puuc). No deja de sorprender esta situación si se considera que entre Kohunlich y Dzibanché hay tan sólo $25 \mathrm{~km}$ de distancia en línea recta. Vistos exclusivamente desde la perspectiva de sus 


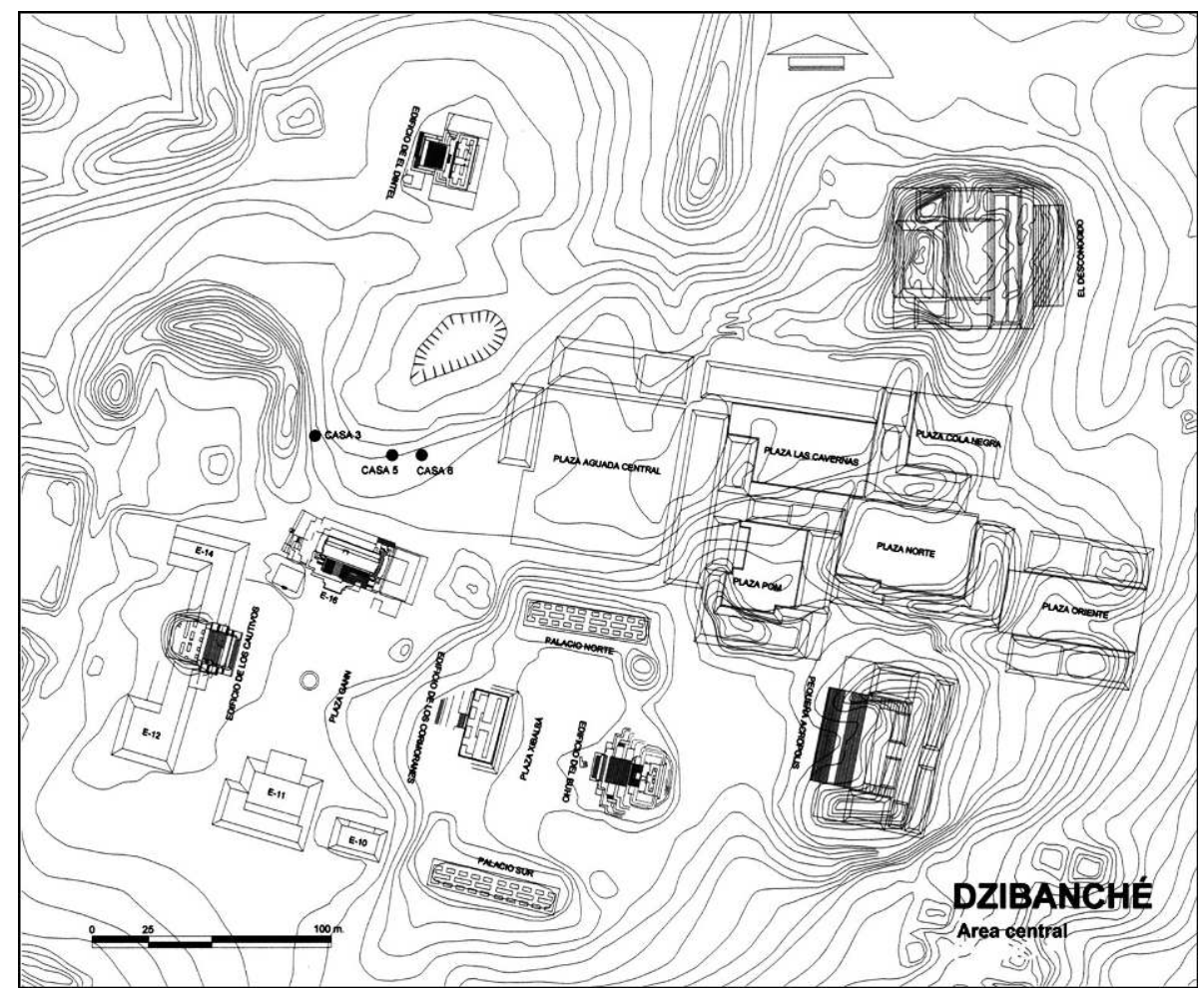

Fig. 12 - Plano del área central de Dzibanché.

respectivas arquitecturas del Clásico tardío, resulta evidente que se trata de dos sitios con desarrollos que poco o nada tienen en común (Figura 13).

En Dzibanché los estilos dominantes en el Clásico medio y comienzos del tardío son de carácter local. Entre ellos destaca el de las pilastras pareadas, caracterizado por la decoración de sus templos a base de paneles limitados por pilastras en pares, bóvedas muy altas de doble desarrollo, y tensores en los extremos de las estrechas crujías internas, así como por sus basamentos de cuerpos con tableros enmarcados y apoyados en taludes basales. De este tipo de arquitectura sólo tenemos conocimiento de una estructura en Calakmul; en Dzibanché existen al menos cinco ejemplos, todos ellos de arquitectura monumental. Tal y como hemos señalado en otros textos, este estilo es del Clásico medio (450-600 d.C.) y está fuertemente asociado a la dinastía Kan en Dzibanché (Nalda y Balanzario 2008; Figuras 14 y 15). 


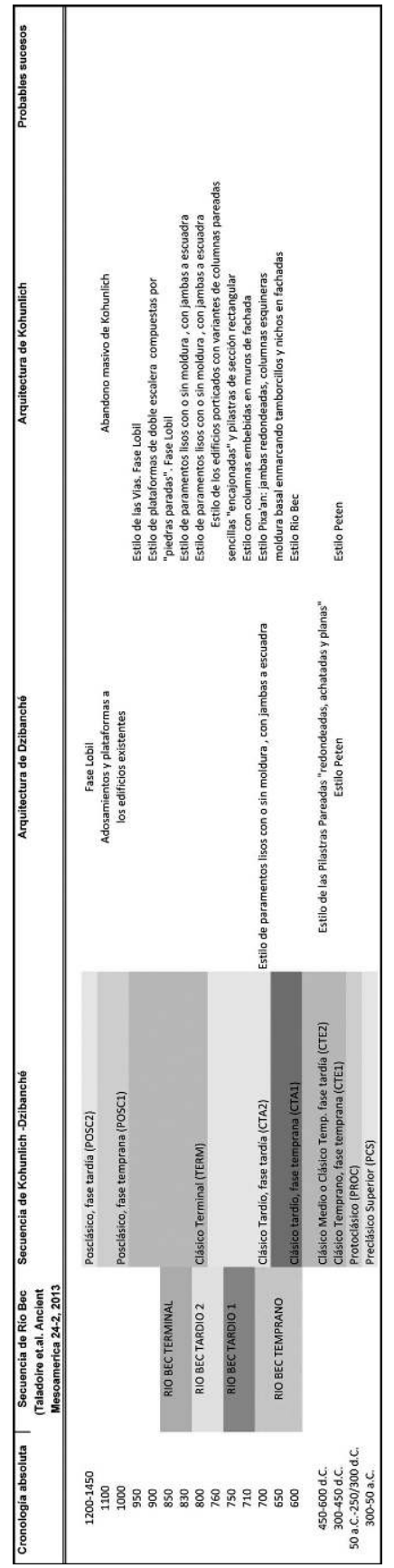

FIG. 13 - Cuadro comparativo de las secuencias estilísticas de Río Bec, Dzibanché y Kohunlich. 


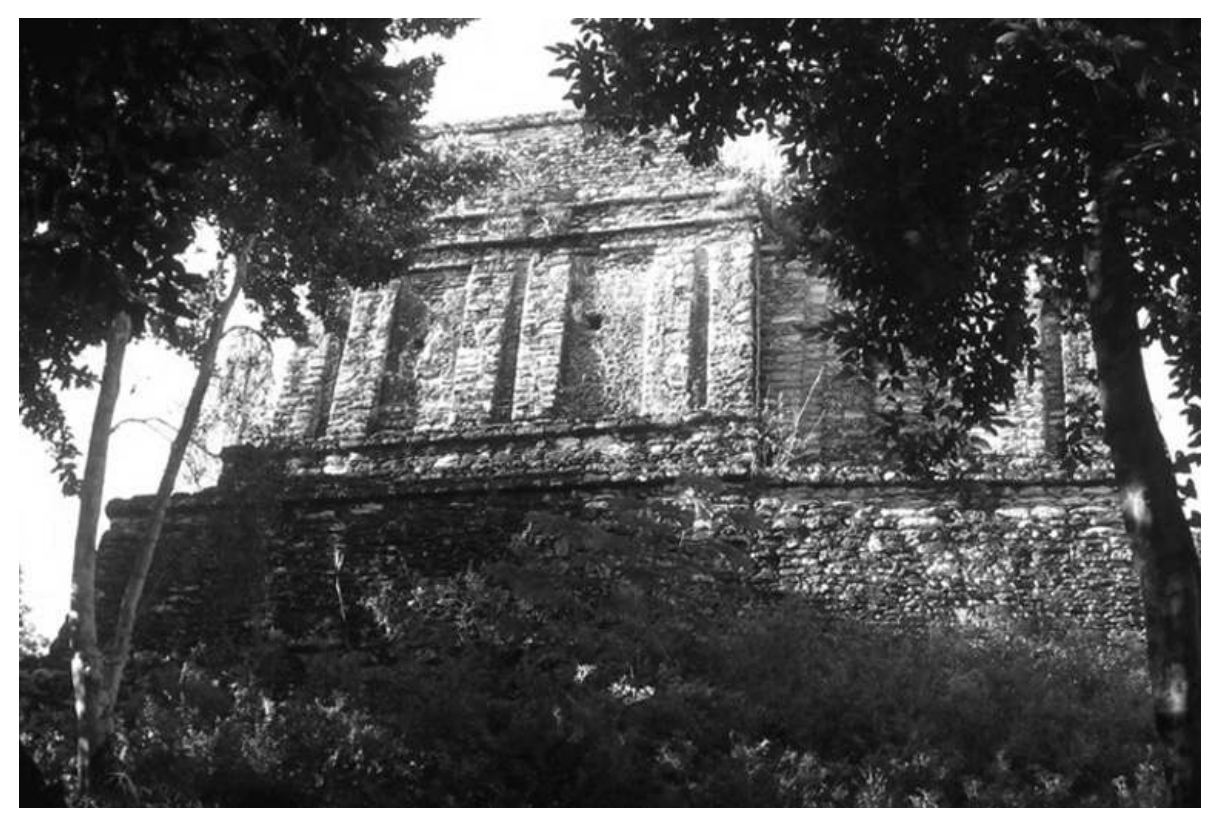

FIG. 14 - Dzibanché, Edificio E2, «Templo de los Cormoranes », detalle de la fachada norte del templo (fotografía cortesía del Proyecto Arqueológico Dzibanché-Kohunlich 2004).

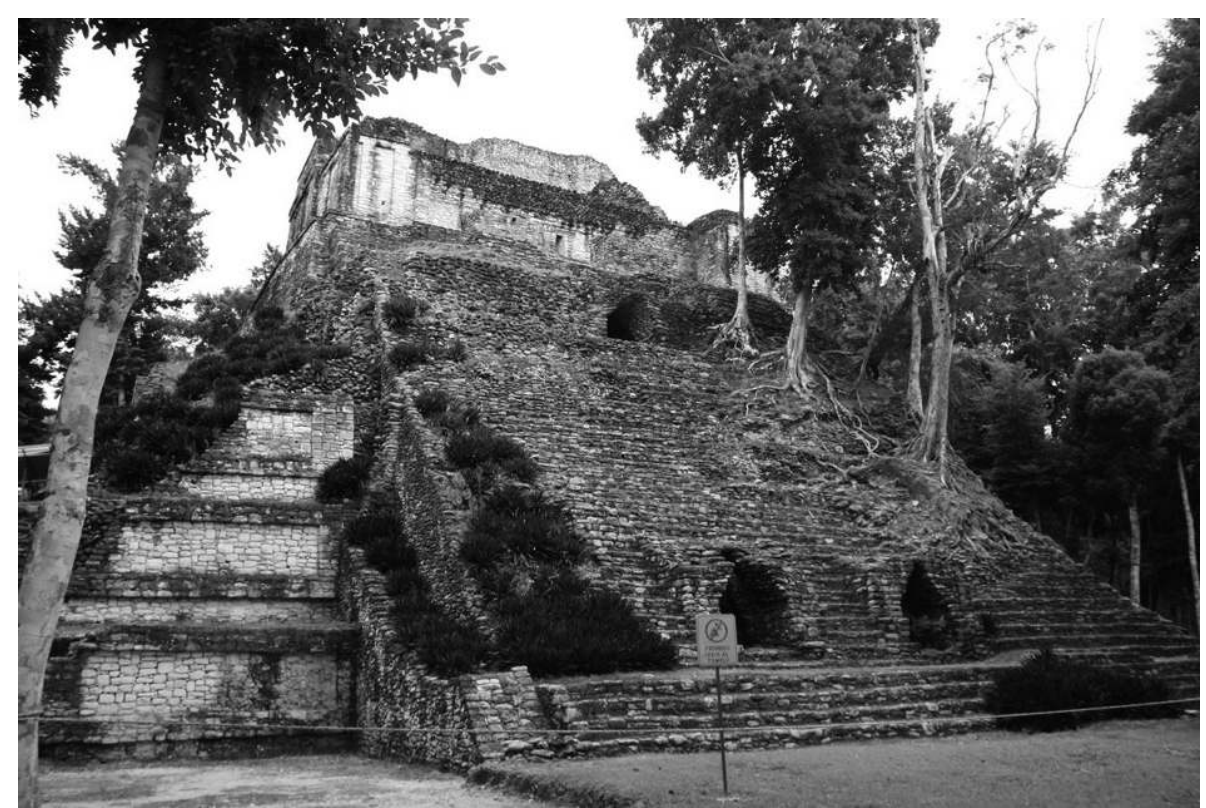

Fig. 15 - Dzibanché, Templo y basamento del Edificio E2, fachada principal (occidente) (fotografía cortesía del Proyecto Arqueológico Dzibanché-Kohunlich 2009). 
En residencias de elite de esta misma época o un poco más tardías, es posible encontrar una arquitectura a base de molduras remetidas y esquinas redondeadas que, aunque distantes, recuerdan las molduras delantal y las combinaciones de moldura basal remetida-doble talud, típicas de la arquitectura petenera. Ninguno de estos estilos se encuentra en Kohunlich, ninguno guarda relación formal alguna con los estilos contemporáneos de Río Bec o Pixa'an.

No será sino hasta la segunda mitad del Clásico tardío y el terminal, que aparecerán en Dzibanché rasgos arquitectónicos aislados que podrían tener como referente a los estilos Río Bec o Pixa'an. No aparecerán, sin embargo, estructuras de fachadas con columnas embebidas ni edificios dispuestos en « vías », como en Kohunlich.

Tales diferencias obligan a preguntar, primero cómo es que la onda expansiva del estilo Río Bec haya alcanzado lugares tan remotos hacia el este, como Nicolás Bravo y Kohunlich, sin afectar sitios como Dzibanché, y, en especial, cuáles fueron las situaciones y mecanismos que produjeron ese patrón que desafía la racionalidad del modelo de gravedad según el cual los sitios de tamaño menor caen en la órbita de los sitios mayores más próximos. Y, segundo, ¿cuál es la razón de que la difusión del estilo Río Bec haya sido más intensa hacia el norte, hacia la zona Chenes, y de que haya tenido poca penetración en el resto de las direcciones? En especial habría que preguntarse sobre la razón detrás del hecho de que en Dzibanché el estilo Río Bec haya pasado inadvertido o, en todo caso, haya sido adoptado parcial y tardíamente.

\section{Los nuevos hallazgos en Dzibanché}

Cualquier respuesta a estas preguntas tiene que partir, forzosamente, de la tesis de que la arquitectura la cual, como cualquier otro rasgo cultural significativo, tiene como referente a la totalidad social y al individuo creativo y ejecutor de variantes, es unindicador potencialde orígenes y alianzasy, aunque temporalmente desfasada respecto al cambio social que podría reflejar, también es un indicador de sometimientos.

Es preciso señalar, primero, que a diferencia de la arquitectura propia de las regiones Chenes y Puuc, la del estilo Río Bec, caracterizada en esencia por sus torres piramidales con escaleras falsas, rematadas o no por templos igualmente falsos, se centra en un área relativamente bien definida en la que destacan los sitios de Xpujil, Hormiguero, Río Bec, Okulhuitz y Payan, entre otros. Es también importante hacer notar que las fechas que se tienen para ese estilo, como estilo dominante en pleno desarrollo pertenecen a la primera mitad del siglo viI, fecha en la que Calakmul vivía su clímax demográfico: es en esa época cuando se talla la mayor parte de las estelas encontradas en ese sitio (Martin y Grube 2000). La región nuclear del estilo Río Bec, y Calakmul, podrían, de esta manera, 
pensarse como dos grandes focos de desarrollo de inicios del Clásico tardío, autónomos, con propuestas diferentes en cuanto a organización del espacio, cultura material y, sobre todo, con capacidad de someter o influenciar a pueblos vecinos y distantes.

Creemos ahora que en esa misma época (600/650-800 d.C.) existía en la región un tercer foco, el de Dzibanché. La idea está basada en la información que está siendo generada con los nuevos trabajos arqueológicos que se vienen realizando en este sitio, información que sin duda requiere de un análisis más profundo pero que estimamos ser suficiente para la construcción de una hipótesis alternativa sobre la cuestión de la dispersión del estilo Río Bec a partir de su área nuclear.

Éramos de la opinión que, con la reubicación de la dinastía Kan en Calakmul hacia el primer cuarto del siglo viI, Dzibanché había entrado en una especie de letargo social caracterizado, en esencia, por una caída sensible en el ritmo de construcción en los espacios públicos; por una contracción del área ocupada por las unidades habitacionales del común de la gente; $y$, en general, por un debilitamiento del poder y roles que hasta entonces había ejercido la elite. Paralelamente se habría producido una declinación paulatina de la importancia de Dzibanché en la región, declinación que se habría acentuado hasta el abandono del sitio en el Posclásico tardío.

Los nuevos trabajos en Dzibanché (2008-2009) están descalificando estas ideas que, en gran medida, parecerían tener como origen el haber concedido demasiada importancia a la dinastía Kan y, en particular, a su aparición tardía en Calakmul. Las nuevas excavaciones han puesto al descubierto residencias de elite de evidente monumentalidad, construidas en el Clásico medio e inicios del tardío (550-650), así como edificios de carácter administrativo, igualmente masivos y de la misma época, que hacen de Dzibanché un sitio de gran importancia aun después de la supuesta reubicación de la dinastía Kan en Calakmul. Cuestionan, de hecho, la idea de una reubicación de esa dinastía en Calakmul, al menos tal y como hasta ahora la habíamos pensado.

Los nuevos trabajos se han centrado en la Pequeña Acrópolis y la Plaza Pom (Figura 12). La primera es un conjunto de cuatro estructuras de muros lisos y frisos decorados con figuras de estuco modelado, entre ellas rostros humanos, monstruos y glifos. Su arquitectura, más bien austera, impresiona por su monumentalidad. El edificio principal en el conjunto mide 60 metros de punta a punta. Es el de mayor longitud en Dzibanché; tiene dos galerías sin divisiones (Figuras 16 y 17) aplanados de estuco de color rojo decorados con cenefas en color ocre y está flanqueado por dos estructuras que más que construcciones independientes parecerían ser extensiones del primero. Al frente, cerrando el paso al edificio principal, se levanta una cuarta estructura de una sola galería. Llama la atención en este conjunto el que ninguno de los edificios fue equipado con banquetas; esta característica, por sí sola, sugiere que el conjunto fue proyectado 


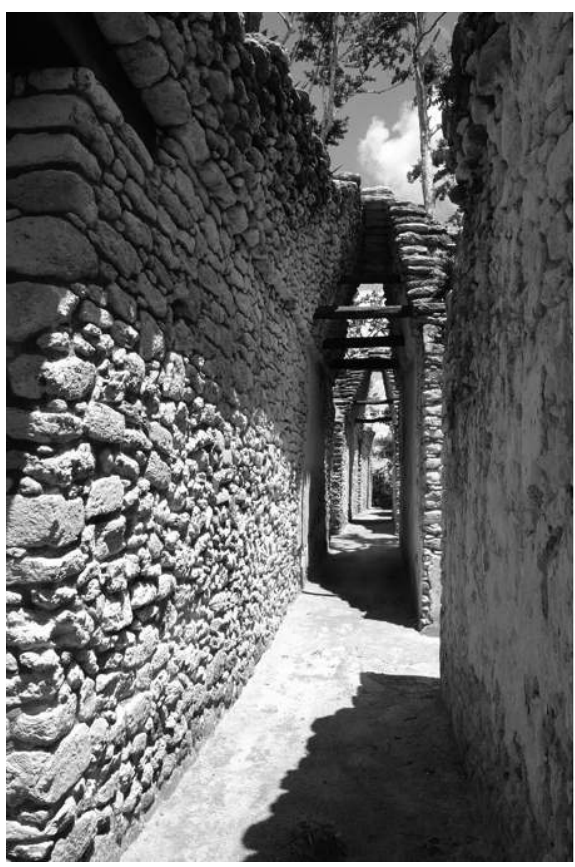

FIG. 16-Dzibanché, Pequeña Acrópolis, Edificio Poniente, galería interna (fotografía cortesía del Proyecto Arqueológico Dzibanché-Kohunlich 2009).

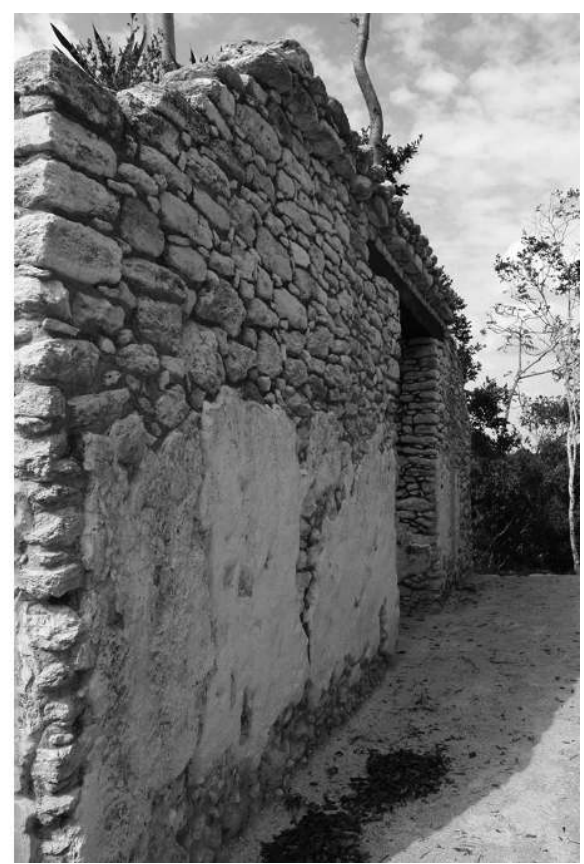

FIG. 17-Dzibanché, Pequeña Acrópolis. Edificio Poniente, fachada principal (fotografía cortesía del Proyecto Arqueológico Dzibanché-Kohunlich 2009).

para satisfacer necesidades distintas de las de habitación. Igualmente llamativo es el hecho de que sus paredes estén cubiertas de grafiti, de naturaleza figurativa o abstracta, que tocan temas diversos. No se trata de dibujos realizados cuando el edificio ya había sido abandonado pues, en algunas áreas se notan dos capas de estuco sobrepuestas con grafiti en ambas, lo que significa que el edificio estaba recibiendo mantenimiento mientras sus paredes se llenaban de grafiti y, por otro lado, que los grafiti no se realizaban para la posteridad. Esto, más el hecho de que los grafiti fueron hechos por personas sin habilidad especial para el dibujo, sugiere que fueron realizados al momento de hacer alguna presentación en el contexto de algún acto oficial de audiencia, en los espacios cubiertos por los edificios de la Pequeña Acrópolis, es decir que fueron símbolos que apoyaban o asentaban un argumento o una petición que se iba a presentar. Todo ello refuerza la idea que los edificios de la Pequeña Acrópolis tuvieron función administrativa, que el conjunto arquitectónico operó como espacio abierto en el que se resolvían cuestiones mundanas y, quizás, donde se ventilaban las relaciones con otros centros de poder. 
La Plaza Pom es un conjunto de cinco edificios alrededor de una plaza. Todos fueron decorados profusamente a base de estucos modelados con representaciones de deidades y personajes diversos, y registros con glifos, entre ellos el glifo emblema de la dinastía Kan (Figura 18). A diferencia de los ubicados en la Pequeña Acrópolis, todos los edificios en la Plaza Pom fueron equipados con banquetas, circunstancia que obliga a pensar que el conjunto sirvió de residencia de personas relacionadas entre sí por vía parental o por afinidad ocupacional. Por las dimensiones del cuarto en el que se encuentra, por su diseño especial -más elaborado de lo normal-y por la posición relevante que ocupa en el edificio principal del conjunto, llama la atención la banqueta tipo «trono » ubicada en el eje mayor del edificio situado en el costado sur de la plaza (Figura 19). Es de hacerse notar, adicionalmente, que si acaso en algún momento la Plaza Pom podía accederse con relativa facilidad, con el tiempo el acceso quedó bloqueado casi en su totalidad.

Después de mucho trabajo de excavación en este conjunto habitacional, no hemos encontrado sino un estrecho pasadizo que comunica la Plaza Pom con edificios en su exterior: todos los vanos que comunicaban esa plaza con los espacios adyacentes, la Plaza Norte y la Plaza Poniente, fueron tapiados. El pasadizo que se habilitó cruza, por cierto, un conjunto de cuartos que obliga a un zigzagueo antes de alcanzar la plaza. Después de ese paseo, quien deseara llegar al personaje que ocupaba el cuarto central del Edificio Sur ascendería por una escalera que, en algún tiempo, parece haber sido cortada a fin de obligar el paso por dos angostas e incómodas escaleras habilitadas a ambos extremos del edificio. Todo ello evidencia que cuarto y banqueta al centro del edificio principal de la Plaza Pom corresponden a una posición de mando y control. Y no sólo sobre quienes ocupaban el resto de los edificios en la Plaza Pom, sino, a juzgar por su posición respecto a la Pequeña Acrópolis, locus de la burocracia y del centro ideológico de Dzibanché, es decir la Plaza Xibalba y la Plaza Gann, sobre todo el sitio y su dominio. La Plaza Pom sería, de esta forma, no solamente un conjunto residencial de elite sino, muy probablemente, la residencia del $k^{\prime} u h u l$ ajaw de Dzibanché.

La idea está reforzada por el descubrimiento adicional del glifo emblema Kan en una vasija de cerámica del Clásico tardío, faceta temprana, en el interior del edificio que ocupa el extremo norte de la Plaza Pom. Una lectura preliminar de los glifos esgrafiados en la vasija (hecha por Velásquez, com. pers. 2009) da cuenta de un kalomte y de un hermano mayor del señor de la dinastía Kan. Es temprano para hacer una propuesta de interpretación del significado de estos glifos, por ello nos limitamos a señalar que a comienzos del Clásico tardío existía más de un personaje asociado a la dinastía Kan y que uno de ellos, quizás el descrito en la vasija como hermano mayor, vivía en Dzibanché. De ser así, no sería extraño el que en el siglo vil se hubiese dividido la dinastía Kan y que quienes ostentaban el título de k'uhul ajaw en Calakmul no fueran sino una rama de esta dinastía, no 


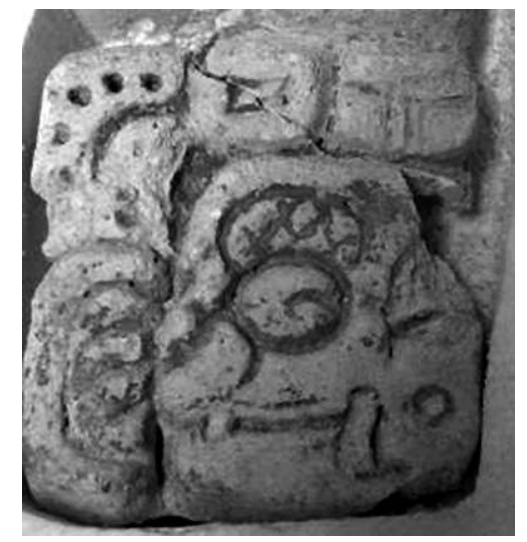

FIG. 18 - Dzibanché, Plaza Pom, Edificio Sur, estuco en relieve del glifo emblema de la dinastía Kan (fotografía cortesía del Proyecto Arqueológico Dzibanché-Kohunlich 2009).

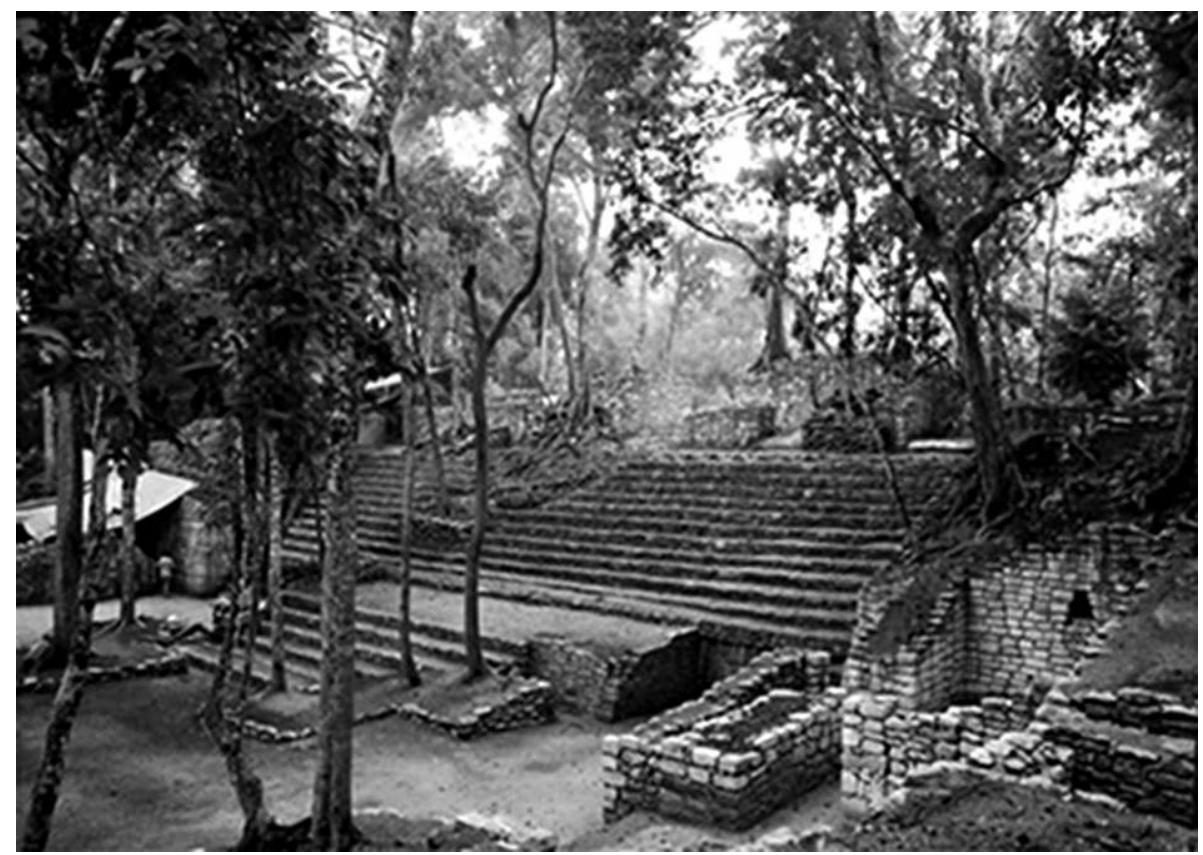

FIG. 19 - Dzibanché, Plaza Pom, vista general del Edificio Sur (fotografía cortesía del Proyecto Arqueológico Dzibanché-Kohunlich 2009). 
necesariamente producto de una escisión violenta si nos atenemos a la forma incluyente en la que se presenta el glifo Kan en la inscripción de la vasija mencionada. No se llega, sin embargo, a la misma conclusión si basamos nuestro juicio en la información contenida en los estucos modelados del Juego de Pelota 2 (véase infra). Al respecto, es de hacerse notar que la estratigrafía y los materiales contenidos en el Edificio Sur de la Plaza Pom indican que ese edificio fue construido sobre una estructura del Clásico temprano y que el cuarto y banqueta que habrían sido residencia del k'uhul ajaw de Dzibanché fueron construidos en la fase Bejuco de la secuencia de Becán, es decir, entre 600 y 700 d.C., fecha compatible con el primer acercamiento que estamos haciendo a la interpretación de estos glifos.

\section{UNA POSIBLE INTERPRETACIÓN DE LAS DIFERENCIAS ENTRE SECUENCIAS DE Dzibanché y Kohunlich}

Existen evidencias que sugieren que en Dzibanché, a comienzos del Clásico tardío (hacia 700 d.C.) se confrontaron grupos de intereses antagónicos. Si uno se atiene al hecho de que los rostros de los personajes portadores de símbolos asociados al poder fueron totalmente destruidos en el friso del Juego de Pelota 2, mientras que el único individuo de estatus menor en ese mismo friso fue respetado (Figura 20), es posible inclinarse hacia la posibilidad de que el enfrentamiento no fue entre grupos de poder integrantes de uno o de diferentes grupos dinásticos, sino entre la elite gobernante y lo que podríamos llamar la base social. Esta idea está reforzada por el hecho de que ninguno de los cautivos encontrados en el Edificio de los Cautivos de la Plaza Gann de Dzibanché, sufrió agresión alguna a pesar de que seguramente estuvieron a la vista en la época en que se dieron los enfrentamientos de inicio del Clásico tardío. Una suerte diferente, por cierto, habría tenido el estuco del Clásico medio del personaje con cuerpo de jaguar reticulado portando antorchas cruzadas en el Edificio T2 de Tutil: su rostro, y sólo su rostro, fue destruido en su totalidad como lo fueron los personajes en el friso del Juego de Pelota 2 (Nalda y Balanzario 2007; Figura 21).

Es innegable, por tanto, que en el Clásico tardío debió haberse producido en Dzibanché (y seguramente en toda la región, dada la importancia de Dzibanché en esa época) una desestabilización política y un consecuente sentido de inseguridad que habría orillado a algunos de los sitios de la región a buscar aliados y protección en otros lugares. Kohunlich habría sido uno de esos sitios. Ese sería el momento de la intrusión de la cultura material asociable a la región del Río Bec. Se trataría sin embargo de una crisis de corta duración aunque de fuerte impacto en la región, pero de la cual Dzibanché se recuperaría pronto, con permanencia o ausencia de la dinastía Kan en el sitio, o, más probablemente, con una rama de esa dinastía asentada en Dzibanché. 


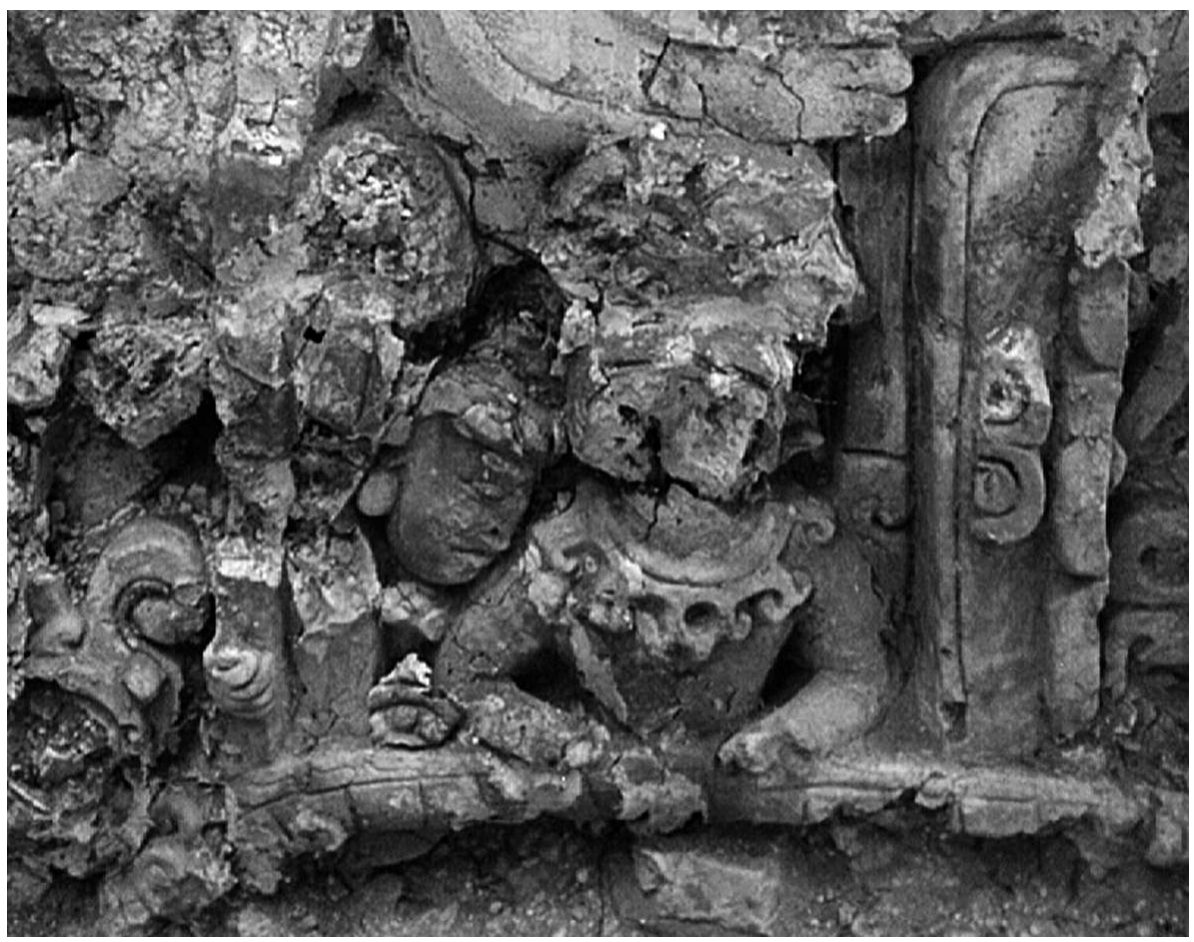

FIG. 20 - Dzibanché, detalle del friso de estuco del Juego de Pelota 2 (fotografía cortesía del Proyecto Arqueológico Dzibanché-Kohunlich 2003).

En esos tiempos Kohunlich había dejado atrás el sistema político altamente centralizado, evidente en la arquitectura monumental des años previos (e.g., Plaza Yaxná, Templo de los Mascarones) y habría entrado a un sistema cuyo reflejo material se encuentra en el palacio del Complejo Pixa'an y el edificio que ocupa el borde poniente de la Plaza de la Estelas (Edificio B2 «El Rey » Figuras 2 y 22). Este último es transicional y hasta atípico, en el sentido de consistir de un templo en el estilo Pixa'an -comúnmente hallado en espacios habitacionalesrematando un alto basamento piramidal, arreglo común en el Clásico temprano. La aparición en Kohunlich de los estilos Río Bec y Pixa'an corre, entonces, paralela a la desestabilización política en Dzibanché; según nuestra tesis consecuencia de ella.

Lo que sucede en Kohunlich inmediatamente después de la aparición del estilo Pixa'an es una restructuración del sistema social hacia una fuerte fragmentación del poder. Los entierros de personajes notables se hicieron en unidades habitacionales presididas por palacios. Uno de esos entierros fue practicado en el relleno de un edificio post-estilo Chenes: es un gobernante del momento, 


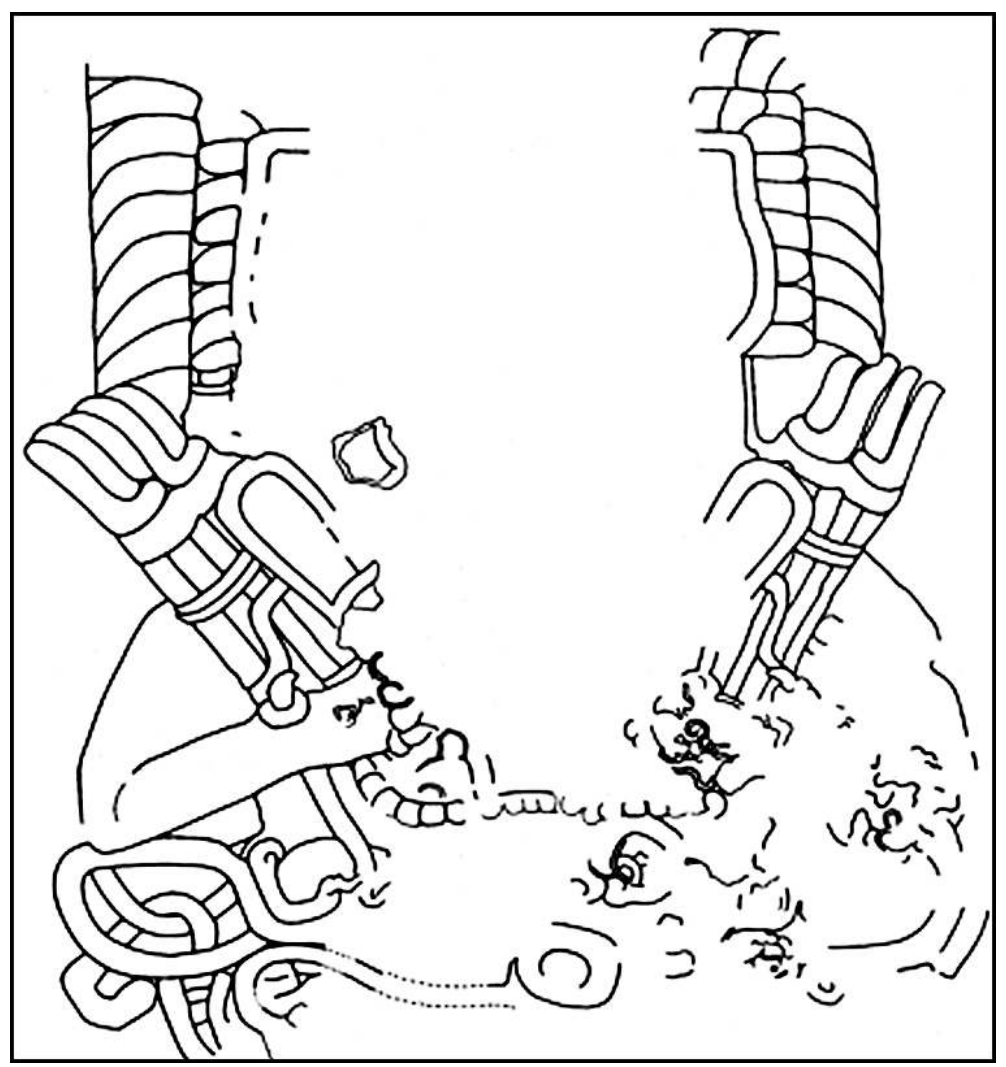

FIG. 21 - Dzibanché, Conjunto Tutil, Edificio T2, mural de estuco localizado en la crujía interna. Dibujo de Sandra B. Balanzario (Proyecto Arqueológico Dzibanché-Kohunlich 2007).

depositado con un par de platos de bordes encontrados labio contra labio, uno de ellos con un glifo que ha sido leído hiin kajaw, " este es nuestro señor » (Velásquez 2002). La posición de la tumba en el edificio principal del Conjunto de los 27 Escalones, lo elaborado de su cámara mortuoria y la relativamente rica ofrenda que lo acompañó fueron suficiente prueba del estatuto del personaje enterrado. Comparado con los enterramientos del Clásico temprano realizados en grandes basamentos piramidales acompañados con ofrendas suntuosas, entierros en palacios como éste distaban mucho de obviar la importancia del individuo inhumado. 


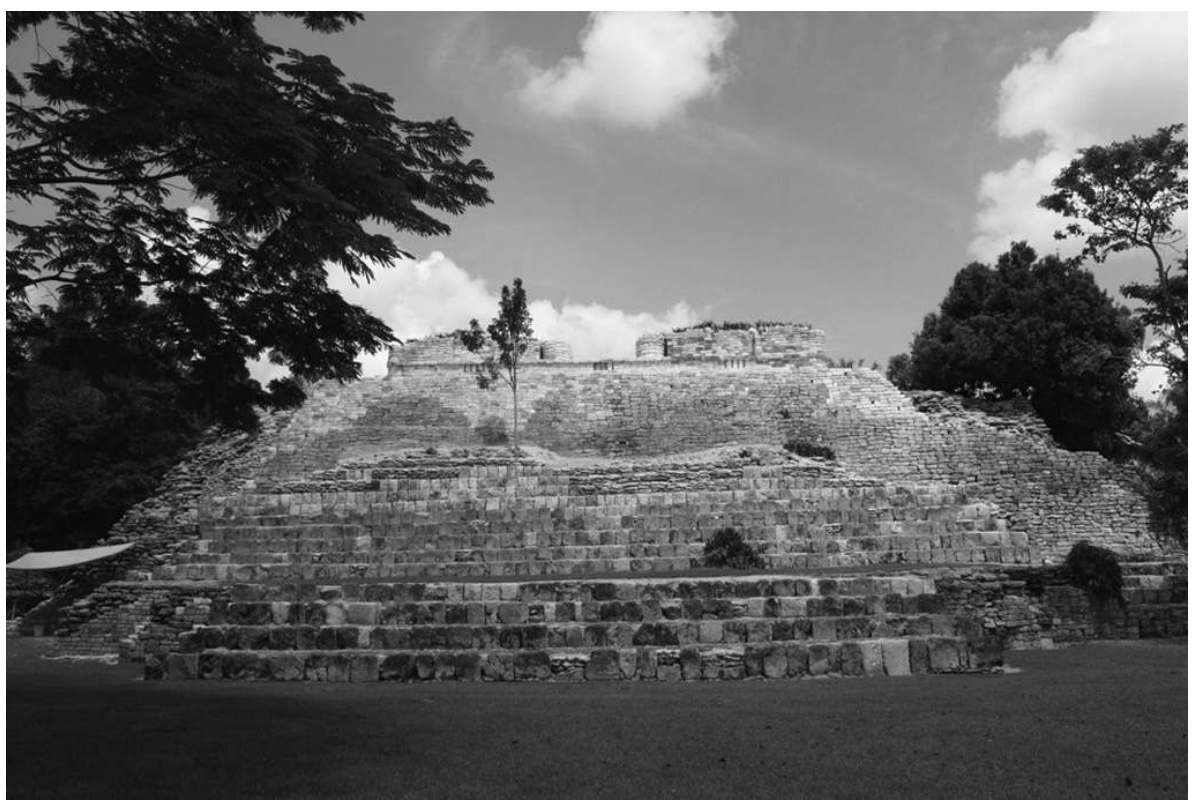

FIG. 22 - Kohunlich, Plaza de las Estelas, Edificio B2 « El Rey », fachada principal (fotografía cortesía del Proyecto Arqueológico Dzibanché-Kohunlich 2009).

En Dzibanché, la intensidad de la actividad constructiva de principios del Clásico tardío (600-700 d.C.) demuestra que la desestabilización mencionada tuvo que haber sido de corta duración. Pronto se habría recompuesto el poder político y pronto se habrían sometido las relaciones sociales a una fuerte centralización. La nueva recomposición se habría llevado por la ruta de la vieja tradición arquitectónica petenera. Aparentemente se trataba de distanciarse del proceso político que comenzaba a desarrollarse en el poniente y norte de la península de Yucatán, desarrollo que culminaría con la aparición de nuevos centros de poder y de renovación cultural (Becán, Río Bec, Kohunlich) que opacaría lo que hasta el Clásico medio había tenido como protagonista a las tierras bajas del sur. Desde la perspectiva de la arquitectura de Dzibanché habría sido, por llamarlo de alguna manera, un « renacimiento » estratégico.

En nuestra opinión, la presencia Río Bec en Kohunlich es un fenómeno de corta duración, es un estilo incipiciente y parece responder a la necesidad de crear condiciones de estabilidad en un momento en que el panorama regional se mostraba confuso y que el tercer polo de desarrollo, el de Dzibanché, había desaparecido momentáneamente. En efecto, con la aparente estabilización de la dinastía Kan en Dzibanché, los problemas de seguridad de Kohunlich se habrían 
agudizado, estando este último centro demasiado cerca del viejo centro de poder y demasiado lejos del aliado o aliados al que habían recurrido en busca de protección. Lo que interpretamos como fragmentación, o sea la reconversión arquitectónica hacia formas compatibles con lo que se estaba desarrollando en ese momento en Dzibanché, parece haber sido el recurso formal al que se apeló como muestra de al menos una neutralidad sin pérdida de la relativa autonomía ganada por Kohunlich en el momento de la declinación momentánea de Dzibanché.

Se trataría de una autonomía política, que no habría que confundir con la que Kohunlich siempre tuvo respecto al desarrollo de su cultura y, en concreto, a la adopción de proyectos arquitectónicos. A todo lo largo de su historia, Kohunlich mostró una relativa autonomía en proyecto arquitectónico: en la época en que el estilo Petén estaba generalizado en toda el área maya, Kohunlich posiblemente estuvo bajo la influencia y dominio de un sitio tan importante como Dzibanché y durante este periodo compartieron el estilo, pero las diferencias de sus variantes particulares son notorias: el Edificio de Los Mascarones en Kohunlich responde con precisión al estilo petenero " típico » del Clásico temprano, tal y como lo hacen, por ejemplo, los Edificios E-11sub2 y E-16sub4 de la Plaza Gann en Dzibanché; ahora bien, las diferencias entre, por ejemplo, estos edificios y los encontrados en Kohunlich alrededor de la Plaza Yaxná son sorprendentes. En Dzibanché no hemos encontrado basamentos de planta elíptica, ni entierros en cámaras rematando basamentos, que sí se construyeron en Kohunlich.

El « momento Pixa'an », igualmente de corta duración, habría quedado atrás y en su lugar habrían aparecido proyectos arquitectónicos donde predominan la austeridad, la simplicidad y la racionalidad en el gasto de la construcción de estructuras habitacionales y de espacios públicos y, sobre todo, una variabilidad que sugiere una preocupación por mostrar una posición de neutralidad en relación con Dzibanché. Durante el Clásico tardío y el terminal, aparece en Kohunlich una fuerte variabilidad cultural que sugiere tolerancia, una falta de compromiso con una línea cultural precisa y, por tanto, con un punto geográfico en particular.

En esa época Kohunlich abrió sus puertas a la migración, y al sitio confluyeron grupos humanos con bagajes culturales sensiblemente diferentes: hacen su aparición las columnas embebidas en muros (Los 27 Escalones, La Gradería, Plaza Merwin), las fachadas porticadas con columnas pareadas (Conjunto del Patio Elevado de la Acrópolis), los edificios de escalera doble (Conjunto de las Vías), las plataformas con escaleras de piedras paradas (Plaza Merwin) (véase Figura 3). Son estilos que se traslapan y convergieron con los existentes, estilos representantes de costumbres y tradiciones de grupos geográficamente distantes entre sí o provenientes de una misma región. Análisis recientes de isotopos estables de estroncio, aplicados en una muestra de 28 osamentas de estatus alto y medio provenientes del Conjunto de los 27 Escalones, permitieron confirmar que 
la mayoría de los individuos (21) son locales, pertenecen a la formación geológica Estero Franco, zona de emplazamiento de Kohunlich, relacionándose el resto de los individuos (7) a la Formación Icaiché, área situada al poniente y centro de la península de Yucatán (Balanzario 2013).

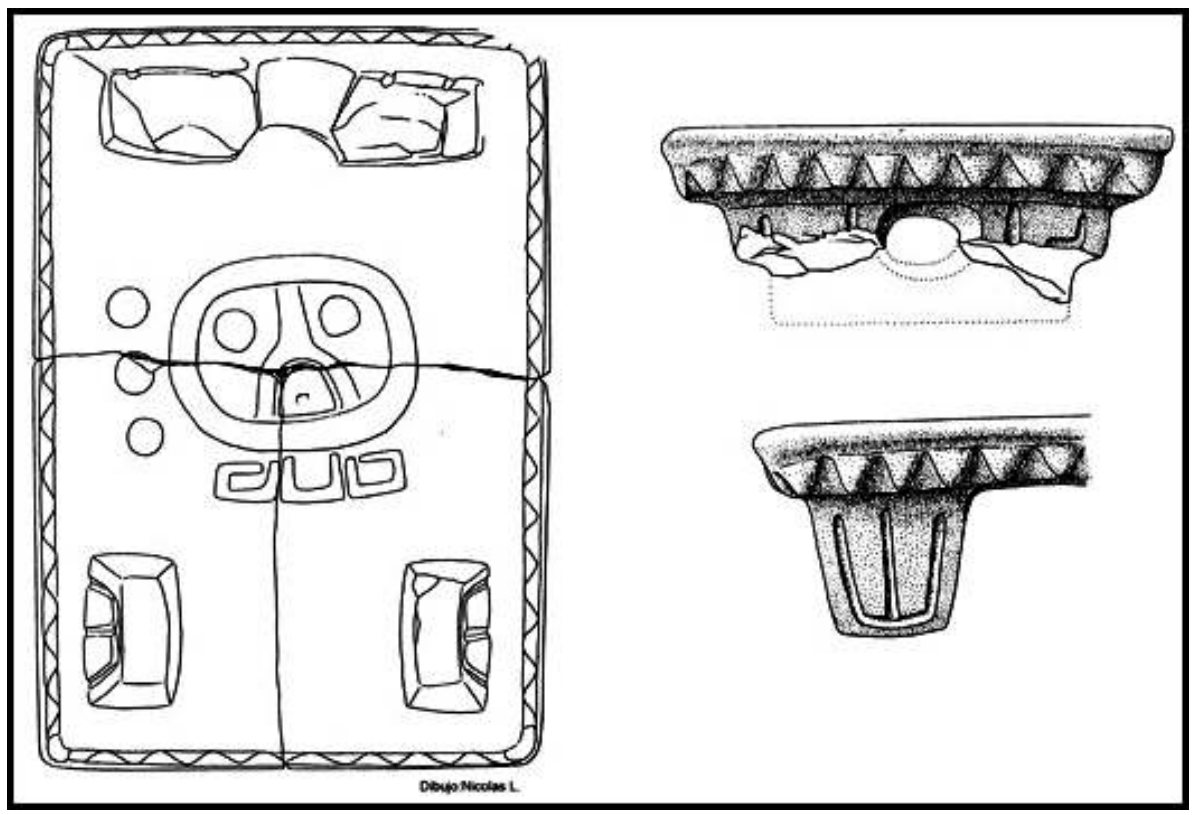

FIG. 23 - Kohunlich, Conjunto Pixa'an, metate miniatura con glifo. Dibujo: Nicolas Latsanopoulos (Proyecto Arqueológico Dzibanché-Kohunlich 1999).

Los resultados obtenidos en el análisis de isotopos estables, la variabilidad de estilos arquitectónicos y el sistema funerario permiten confirmar que en Kohunlich existió la convivencia de varios linajes, producto de alianzas matrimoniales y políticas, los que quizá tuvieron antepasados comunes. En ese sentido, el recurso a la etnografía y las prácticas rituales reseñadas por varios autores de la Colonia sustentan la tesis de la secuencia propuesta que, en términos generales, señala un cambio hacia un poder político compartido, similar al encontrado por los españoles en la región del Petén Itzá, reducto que permaneció insumiso durante la mayor parte de la colonia, hasta 1697; se diferenciaría de ese modelo por el hecho que la rotación del poder se habría dado en Kohunlich entre representantes de los diferentes grupos del mismo origen (quizás étnico si definimos a los grupos étnicos por la identificación que expresan sus integrantes y no necesariamente por compartir una misma lengua) y no por ser miembros de 
pueblos vecinos, al estilo del cuchcabal (Okoshi 2007). Así, el asentamiento de Kohunlich se conformó de entidades políticas cuyo espacio territorial se definió por un conjunto de complejos residenciales, cuyos gobernantes estuvieron enlazados por relaciones de índole política, económica y religiosa.

A finales del Clásico terminal y principios del Posclásico, existió un ambiente de inestabilidad política, consecuencia de la ausencia de un proyecto comunitario que suscribiera los intereses de todos los grupos de origen diverso que integraban a Kohunlich. La presencia de ofrendas, denominadas « acumulacionesinusuales », dispuestas al interior de los conjuntos habitacionales sobre los pisos y en derrumbe (Balanzario 2011), conteniendo restos de figurillas, concha, lítica tallada y pulida, metates miniatura, cerámica, restos óseos humanos ${ }^{4} \mathrm{y}$ de animales, demuestra la realización de ceremonias de carácter ritual. Uno de estos metates miniatura fue roto en tres pedazos, en el dorso fue grabado el glifo 3 Ahau, relacionado con el fin de un katún, inscrito en 869 d.C., fecha relacionada con un momento de indudable crisis social (Figura 23; Balanzario 2004, 2011).

Una proliferación similar de estilos en el Clásico tardío no se manifiesta en Dzibanché sino muy tímidamente. Dzibanché parece pasar rápidamente de un renacimiento vinculado a la dinastía Kan que pudo haberse prolongado todo el siglo vII y quizás parte del vIII, a una pérdida paulatina de importancia en la región y la conversión del gran centro de población en un pequeño asentamiento que termina por extinguirse en el Posclásico tardío, en la fase que Harrison (1981) bautizó con el nombre de Lobil (Nalda y Balanzario 2010). *

* Manuscrit reçu en mars 2014, accepté pour publication en octobre 2014.

\section{Notes}

1. El complejo arquitectónico de la Acrópolis, denominado originalmente por Merwin (1913), corresponde al producto de una larga actividad constructiva desarrollada durante el Clásico tardío y terminal. No corresponde al tipo de edificio al que se le aplica una denominación dentro de la arquitectura maya, pues no se trata de la superposición de estructuras dentro de una composición tríadica. La mayor parte del complejo fue explorado por Víctor Segovia y Aracely Pérez a mediados de los años 1970; no existe ningún informe; la única información fue recuperada con los trabajadores del poblado de Francisco Villa. En 1993-1994, se realizaron exploraciones en la mitad oriente del Conjunto Patio Elevado, que junto con la realización de pozos estratigráficos permitieron conocer la secuencia estratigráfica del basamento de la Acrópolis y de los edificios que la rematan (Nalda et al. 1997, vol. I-A).

2. Durante el Clásico tardío (650-700 d.C.), las galerías de la Acrópolis fueron rellenadas, sus fachadas fueron cubiertas con nuevos paramentos lisos en talud, cubiertos con gruesos aplanados de estuco de color rojo. Sobre este gran basamento, fueron construidos los edificios del Conjunto del Patio Elevado. Para acceder a este conjunto hay que ascender por una amplia escalera, ubicada en la fachada poniente, accediendo a través de un pasillo abovedado. Los once edificios que componen este conjunto, están localizados alrededor de un patio central. 
3. Enrique Nalda considera una población de «entre 5,000 y 10,000 habitantes para el clímax demográfico del sitio, cantidad calculada por estimación del número de personas que pueden ocupar cómodamente los espacios interiores de las estructuras de función doméstica, durmiendo sobre las banquetas o directamente sobre bastidores o esteras colocadas en el piso de los cuartos. El rango relativamente amplio en el estimado se debe a que, aunque en Kohunlich se ha explorado un área habitacional inusualmente grande y se ha sondeado extensivamente el área, no todas las estructuras están fechadas con exactitud» (Nalda 2004, pp. 36-37). Para el clímax del Clásico tardío-terminal, la estimación está basada en el análisis de espacios contenidos en los complejos habitacionales de Los 27 Escalones y los Conjuntos Noroeste y Pixa'an, todos de esa misma época, y la extrapolación de estos datos, considerando que en Kohunlich existen al menos 20 de estos complejos. Habiendo contabilizado una población de alrededor de 250 personas en cada uno de estos conjuntos y tomando en cuenta que una parte de la población vivía en zonas fuera de complejos habitacionales del tipo referido, la cifra mínima asciende a 5,000 personas para el área central de Kohunlich (Nalda, com. pers. 2004).

4. A este periodo pertenecen los entierros depositados debajo de los pisos de estuco, pertenecientes a la última época constructiva del edificio. Este tipo de entierros se caracteriza por la ausencia de determinados huesos. En uno de los entierros encontrados en Kohunlich (Entierro no. 2), se observó la ausencia de fémures, tibias y peronés, en tanto que los huesos de los pies se encontraron completos y en relación anatómica. La disposición de los restos óseos permite pensar que se trata de una intrusión, con el retiro cuidadoso de los huesos faltantes, y no de una simple vandalización de la tumba y su contenido. $\mathrm{Al}$ respecto, en las acumulaciones inusuales se encontraron restos óseos desmembrados pertenecientes a varios individuos con huellas post mortem. El tipo de manipulación del entierro representa un ceremonial que trataría de la recuperación del poder depositado en los huesos, del reconocimiento de la importancia del personaje enterrado y de su potencial en la realización de una ceremonia propiciatoria (Balanzario 2004).

\section{REFERENCIAS CITADAS}

ANDREws George F.

1985 "Chenes-Puuc architecture: chronology and cultural interaction », Arquitectura y Arqueología. Metodologías en la cronología de Yucatán, CEMCA (Études mésoaméricaines, série II, 8), México, pp. 11-39.

1987 «Architecture at Kohunlich, Quintana Roo. A preliminary report», Cuadernos de arquitectura mesoamericana, 10, pp. 16-32.

1994 «Architectural survey of the Rio Bec, Chenes, and Puuc regions: progress and problems ", in H. J. Prem (ed.), Hidden among the hills. Maya archaeology of the Northwest Yucatan Peninsula, Verlag von Flemming, Bonn, pp. 247-288.

BALANZARIO Sandra

2004 Kohunlich: Acumulaciones inusuales de materiales arqueológicos, tesis de licenciatura, ENAH, México.

2011 "Kohunlich: Acumulaciones inusuales de materiales arqueológicos ", in E. Nalda (ed.), Kohunlich: Acumulaciones inusuales y Figurillas, INAH (Colección científica, 586), México, pp. 13-153.

2013 Sistemas políticos del Clásico en Kohunlich, Quintana Roo, tesis de doctorado, Escuela nacional de antropología e historia, México [en prensa]. 
GENDROP Paul

1983 Los estilos Río Bec, Chenes y Punc en la arquitectura maya, UNAM, México.

1987 "Nuevas consideraciones en torno a los estilos Río Bec y Chenes», Cuadernos de arquitectura mesoamericana, 10, pp. 39-49.

HARRISON Peter

1981 "Some aspects of preconquest settlement in Southern Quintana Roo, Mexico ", in W. Ashmore (ed.), Lowland Maya settlement patterns, University of New Mexico Press (School of American Research advanced seminar series), Albuquerque, pp. 256-286.

Martin Simon, Nikolai Grube

$2000 \quad$ Chronicle of the Maya kings and queens, Thames and Hudson, Londres.

MERwin Raymond E.

1913 The ruins of the Southern part of the peninsula of Yucatán with special reference to their place in the Maya area, tesis de doctorado, Harvard University, $125 \mathrm{p}$.

NaLDa Enrique

2004 Kohunlich. Emplazamiento y desarrollo histórico, CONACULTA/INAH (Colección científica, 463), México.

Nalda Enrique, Sandra Balanzario

2006 «Diversidad cultural: rasgo fundamental del Clásico tardío de Kohunlich », in A. Barrera Rubio, R. Gubler (eds.), Los mayas de ayer y hoy. Memorias del Primer congreso internacional de cultura maya, Mérida, marzo, 2001, Universidad autónoma de Yucatán, Mérida, pp. 545-559.

2007 «Dzibanché y Teotihuacan: presencias y ausencias », in P. Fournier, W. Wiesheu, T. H. Charlton (eds.), Arqueología y complejidad social, INAH/ENAH, México, pp. 107-128.

2008 Un estilo arquitectónico peculiar en Dzibanché y su posible correlato territorial, in R. Liendo Stuardo (ed.), El territorio maya, INAH, México, pp. 303-321.

2010 «Nuevas consideraciones sobre la fase Lobil», Arqueología, 43, pp. 182-197.

Nalda Enrique, Adriana Velázquez, Sandra Balanzario, Alan Maciel

1997 Kohunlich. Temporada de campo 1993-1994, Archivos del Consejo de arqueología, INAH, México, 6 vol.

Oкоsнi Tsubasa

2007 «La formación de las entidades políticas en las tierras bajas del Posclásico tardío: una nueva perspectiva ", in A. Monod-Becquelin, A. Breton, M. H. Ruz (éd.), Figuras mayas de la diversidad, CEPHCIS/UNAM, Mérida, pp. 507-536.

Pollock Harry E. D.

1970 "Architectural notes on some Chenes ruins", Papers of the Peabody Museum, 61, pp. 1-87. 
1980 The Puuc, Harvard University (Memoirs of the Peabody Museum of American Archaeology and Ethnology, 19), Cambridge.

PotTer David F.

1977 Maya architecture of the Central Yucatán Peninsula, Mexico, Middle American Research Institute, Tulane University (Publication, 44), New Orleans.

SAHLins Marshall D.

1967 "The segmentary lineage: an organization of predatory expansion », in R. Cohen, J. Middleton (eds.), Comparative political systems, The Natural History Press, New York.

Velásquez García Erik

2002 « Nuevo glifo maya en Kohunlich, Quintana Roo », Arqueología mexicana, 9 (54), p. 16.

WALLERSTEIN Immanuel

1997 The modern world system: capitalist agriculture and the origins of the European world economy in the sixteenth century, Academic Press, New York. 
